\title{
Hierarchical stabilization of emulsions with multi- scale interconnected droplets and ultra-low nanoparticle loadings
}

Changqian Cao ( $\sim$ changqiancao@mail.iggcas.ac.cn )

Institute of Geology and Geophysics, Chinese Academy of Sciences https://orcid.org/0000-0002-50694122

\section{Elsayed Abdelphata}

Department of Chemical and Petroleum Engineering, University of Calgary

\section{Aigerim Meimanova}

Department of Chemical and Petroleum Engineering, University of Calgary

\section{Jian Wang}

Canadian Light Source Inc.

Jiacheng Yu

Institute of Geology and Geophysics, Chinese Academy of Sciences

\section{Brandy Pilapil}

Department of Chemical and Petroleum Engineering, University of Calgary

\section{Peng Gong}

Department of Mechanical and Manufacturing Engineering, University of Calgary

\section{Jinlu Zhao}

Institute of Geology and Geophysics, Chinese Academy of Sciences

\section{Yuyang Zhang}

Institute of Geology and Geophysics, Chinese Academy of Sciences

\section{Fengjiao Fang}

Institute of Geology and Geophysics, Chinese Academy of Sciences

\section{Apostolos Kantzas}

Department of Chemical and Petroleum Engineering, University of Calgary

\section{Milana Trifkovic}

Department of Chemical and Petroleum Engineering, University of Calgary

\section{Steven Bryant}

Department of Chemical and Petroleum Engineering, University of Calgary

\section{Yongxin Pan}

Institute of Geology and Geophysics, Chinese Academy of Sciences https://orcid.org/0000-0002-42273061 
Physical Sciences - Article

Keywords: emulsion stabilization, colloidal particles, Pickering emulsions

Posted Date: December 2nd, 2021

DOI: https://doi.org/10.21203/rs.3.rs-1114539/v1

License: (c) (i) This work is licensed under a Creative Commons Attribution 4.0 International License. Read Full License 


\section{Hierarchical stabilization of emulsions with multi-scale interconnected droplets and ultra-low nanoparticle loadings}

Changqian $\mathrm{Cao}^{1 *}$, Elsayed Abdelfatah ${ }^{2}$, Aigerim Meimanova ${ }^{2}$, Jian Wang ${ }^{3}$, Jiacheng $\mathrm{Yu}^{1}$, Brandy K. Pilapil ${ }^{2}$, Peng Gong ${ }^{4}$, Jinlu Zhao ${ }^{1}$, Yuyang Zhang ${ }^{1}$, Fengjiao Fang ${ }^{1}$, Apostolos Kantzas ${ }^{2}$, Milana Trifkovic $^{2}$, Steven L. Bryant ${ }^{2 *}$, Yongxin Pan $^{1}$

1. Key Laboratory of Earth and Planetary Physics, Institute of Geology and Geophysics, Innovation Academy for Earth Science, Chinese Academy of Sciences, Beijing 100029, P. R. China

2. Department of Chemical and Petroleum Engineering, University of Calgary, Calgary, AB, T2N 1N4, Canada

3. Canadian Light Source Inc., University of Saskatchewan, 44 Innovation Boulevard, Saskatoon, SK, S7N 2V3, Canada

4. Department of Mechanical and Manufacturing Engineering, University of Calgary, 40 Research Place NW, Calgary, Alberta T2L 1Y6, Canada

*Corresponding authors: Changqian Cao (changqiancao@mail.iggcas.ac.cn); Steven L. Bryant (steven.bryant@ucalgary.ca)

Pickering stabilization by colloidal particles is a common strategy to disperse droplets of one fluid into another fluid in food, cosmetics and chemical industries ${ }^{1-3}$. For over a century, this kind of stabilization has been governed by constant surface coverage concepts in which particles irreversibly attach to the fluid-fluid interface. The need to cover sufficient interfacial area to prevent coalescence typically results in large loadings of particles, uniform droplet size, creation of rigid interface and closed-cell structure with small total area ${ }^{4-7}$. Here we report a stabilization mechanism that yields hierarchically structured oil-in-brine emulsions with high interfacial area, deformability, connectivity and long-term stability at unprecedentedly low nanoparticle loadings. The hierarchy in structure is achieved via dynamic cation-particle-droplet interactions in cascaded emulsification, which consists of i) formation of submicron oil droplets $(\sim 250 \mathrm{~nm})$ lightly covered by hydrophilic polymercoated iron oxide nanoparticles and polyvalent metal ions; ii) spontaneous formation of small 
droplets of nonpolar oil $(\sim 1 \mu \mathrm{m})$ stabilized by the nanodroplets and cations and iii) attachment of nanodroplet/small droplet clusters to bridge large unarmoured oil droplets (5$50 \mu \mathrm{m})$ in macroemulsions. This new mode of stabilization enables much more efficient use of nanoparticles, stabilizing a given size macroemulsion droplet at an order of magnitude smaller particle loading. Moreover, particle loading decreases with the 5/3 power of droplet size, rather than the first power typical of Pickering emulsions. Finally, cations play a novel and essential role in this mechanism, which cannot be accommodated in the conventional Pickering model. Our approach provides a new pathway for templating materials with better control over the structure, and for exploiting applications that are currently inaccessible for Pickering and surfactant stabilized emulsions.

Biological organisms have evolved to produce a variety of multi-scale hierarchically structured composites (i.e. wood, bone, shell, or grass). Inspired by such natural processes, biomimetic fabrication can lead to synthesis of unique materials with the possibility of multi-scale functionalization for tissue engineering, separation, catalysis, sensing, energy storage and convection $^{8-10}$. Emulsions with controlled strength, droplet sizes and connectivity are candidate soft templates for synthesis of hierarchically porous materials ${ }^{9,11}$. Pickering emulsions stabilized by solid particles have advantages over emulsions stabilized by surfactants because solid particles have low toxicity and larger desorption energies than surfactants and provide a robust mechanical interfacial barrier to droplet coalescence ${ }^{4,12}$. However, current emulsion template requires a high volume fraction $(>0.7)$ of the dispersed phase and high concentration of stabilizers to form crowded droplets trapped in three-dimensional space to induce the interconnectivity ${ }^{6,9,11,13-15}$. For a given particle-fluid-fluid system, the surface coverage of droplets is often invariant, resulting in an inverse relationship between the diameter of emulsion droplet and the loading of Pickering particles $^{16}$ :

$R_{e}=\frac{4 \varphi_{d} R_{p}}{\varphi_{p}}$

where $R_{e}$ and $R_{p}$ are the radius of emulsion droplets and particles respectively and $\varphi_{d}$ and $\varphi_{p}$ are the volume fraction of dispersed phase and particles respectively. Thus a given particle loading $\varphi_{p}$ gives a characteristic droplet size, and decreasing loadings lead to larger droplets, eventually too 
large to remain stable ${ }^{17,18}$. It has long been a major question whether the emulsions can be stabilized with much less particles without sacrificing mechanical properties. Although as little as $5 \%$ surface coverage has been reported in one case if particles form monolayer bridges between droplets $^{19}$, it is well-established that particle should cover $23-91 \%$ of droplet surface area for steric stabilization $^{20}$. The large loadings of particles at the rigid interface not only reduces deformability of emulsion droplets, but also affects forming pore throats during templated synthesis of hierarchically porous materials $\mathrm{s}^{5,6,9,11,13-15,21}$.

We report the fabrication of hierarchically structured oil-in-water emulsions at nanoparticle loadings significantly lower than previously reported thresholds for Pickering emulsions. The mechanism of stabilization differs fundamentally from the classical Pickering concept, resulting in scaling relation different from Eq (1) and 2.6 to 12 times less droplet surface coverage than minimum required by the bridging or steric hindrance mechanisms. The stabilization was achieved through the cascaded emulsification (Fig. 1). At the first level, poly (4-styrenesulfonic acid-comaleic acid)-coated iron oxide nanoparticles (PIONPs) in brine $\left(\mathrm{CaCl}_{2}\right)$ stabilize submicron droplets, ca. $250 \mathrm{~nm}$ in diameter. In the second level, these submicron droplets in combination with polyvalent ions (e.g., $\mathrm{Ca}^{2+}, \mathrm{Co}^{2+}, \mathrm{Ni}^{2+}$, and $\mathrm{Fe}^{3+}$ ) spontaneously form macroemulsion small droplets, ca. $1.3 \mu \mathrm{m}$ in diameter. Finally, these small droplets, in turn, bridge large droplets (5-50 $\mu \mathrm{m}$ ), forming interconnected hierarchically structured oil-in-brine macroemulsion with droplet size from submicron to tens of microns. The hierarchy greatly increase the surface-to-volume ratio, roughness, strength, viscoelasticity and deformability of emulsion droplets, providing an ideal template for the synthesis of hierarchically structured materials. Neither the large droplets nor the small droplets in macroemulsion require any coverage by individual nanoparticles to remain stable. Because remarkably few submicron droplets are sufficient, the overall requirement for nanoparticles is much lower than in conventional Pickering emulsions with the same distribution of large droplets.

\section{Metal ion induced stabilization of submicron oil droplets by PIONPs}

The hydrophilic PIONPs in brine were chosen for the synthesis of submicron-sized droplets to exploit two advantages. First, transmission electron microscopy (TEM) and scanning electron microscopy (SEM) analyses show that PIONPs are quite monodispersed with a median $\mathrm{Fe}_{3} \mathrm{O}_{4}$ core 
size of $11.0 \pm 2.2 \mathrm{~nm}$ and a core-shell diameter of $25.1 \pm 2.2 \mathrm{~nm}$ (Extended Data Fig. 1a-e). They are negatively charged $(-71 \mathrm{mV})$ and notably stable in high ionic strength solution of $\mathrm{CaCl}_{2}$ (Extended Data Table 1, Extended Data Fig. 1f). Second, these PIONPs can pin the oil-water interface after binding calcium ions through carboxylate group of surface polymers. Conversely, free sulfonic groups on PIONPs preserve sufficient negative charge after binding calcium ions to maintain repulsion between particles and dispersion stability (Extended Data Fig. 1f-i).

We made stable submicron-sized droplets by sonicating $15 \%(\mathrm{v} / \mathrm{v}) 1$-octadecene oil and PIONPs of $5.1 \mathrm{wt} \%$ in $0.4 \mathrm{M} \mathrm{CaCl}_{2}$, based on a series of preliminary tests showing that only at the relatively high concentration ( $\geq 4.7 \mathrm{wt} \%$ ) can PIONPs stabilize homogeneous submicron droplets (Extended Data Fig. 2). The oil-in-brine droplets (Fig. 2a) have zeta potential (-23.2 mV) similar to $-25.7 \mathrm{mV}$ of PIONPs in $0.4 \mathrm{M} \mathrm{CaCl}_{2}$ (Extended Data Table S1), have diameters of about 250 $\mathrm{nm}$ (Extended Data Fig. 3), and can be stored in brine for at least 35 d. Cryo-SEM analysis coupled with energy-dispersive $\mathrm{X}$-ray spectroscopy spectra show that single oil droplet is surrounded by PIONPs at the oil-water interface and has a relatively higher concentration of $\mathrm{Fe}, \mathrm{S}, \mathrm{Ca}, \mathrm{C}$, and $\mathrm{O}$ compared with water background, which indicates that PIONPs and calcium ions serve as stabilizers for these tiny oil droplets (Fig. 2b, Extended Data Fig. 4).

As shown in the high-resolution atomic force microscopy (AFM) image acquired in a liquid cell (Fig. 2c), many PIONPs with diameters of $\sim 25 \mathrm{~nm}$ are distributed on the surface of submicron droplet and cover $\sim 26 \%$ of the droplet surface, consistent with the value of $33 \%$ calculated from mass ratios and projected particle area (Extended Data Table S2). PIONPs are not uniformly distributed on the oil-water interface but form disordered networks due to the capillary forces that are particularly pronounced for rough nanoparticles, as confirmed by the liquid-cell TEM image (Fig. 2d). The oxygen-edge scanning transmission X-ray microscopy (STXM) image (Fig. 2e) distinguishes oxygen-rich water from oxygen-free oil while the iron-edge STXM confirms high concentrations and non-uniform distribution of iron atoms at the oil-water interface (Fig. 2f). These observations confirm that the first level of the emulsification is different from the principle of wettability-driven particle adhesion, but these submicron droplets at a coverage typical of Pickering emulsions ${ }^{20}$.

\section{Hierarchical stabilization of oil-in-brine macroemulsions by submicron droplets}


The submicron droplets are less hydrophilic than PIONPs (Extended Data Fig. 5) and have higher affinity for newly created oil/brine interface in the second emulsification step. As shown in the liquid cell SEM images (Fig. 3a), the apparent size of submicron droplets (bright spots) increased with time to form small micron-sized droplets $(\sim 1 \mu \mathrm{m})$ finally around big oil droplets. Liquid cell STXM and LSCM images also clearly show that the submicron droplets tend to assemble at the oil-brine interface to form a small micron-sized droplet structure, which is comprised of several submicron droplets arranged in a ring surrounding a small volume of oil (Fig. 3b-d, Extended Data Fig. 6). These observations provide consistent evidence that the energy barrier creating small droplets is quite low so that the submicron droplets preferentially stabilize such kind of structure due to the strong affinity of the nanoparticles for droplet surfaces at high ionic strength.

We then prepared a macroemulsion through high-shear homogenization of equal parts of 1octadecene oil and $0.4 \mathrm{M} \mathrm{CaCl}_{2}$ brine using the submicron droplets with the effective loadings of $0.1 \mathrm{wt} \%$ PIONPs in the macroemulsion. The macroemulsion remained stable for at least 2 months (Extended Data Fig. 7). As shown in 2-D (Fig. 3e, g, Extended Data Fig. 8) and 3-D reconstructed LSCM images (Fig. 3f), the large droplets $(5-20 \mu \mathrm{m})$ are bridged to form aggregates by several nanometer- to micrometer-sized small droplets ( $1.3 \mu \mathrm{m}$ in Sauter diameter). This observation is further supported by a liquid cell STXM image (Fig. 3h) and AFM image (Fig. 3j) of single large droplet showing that several small droplets reside on the interface of large droplets, occupying $21 \%$ (STXM image) to 24\% (AFM image) of droplet surface. Submicron-sized oil droplets are evident on the surface of small droplets in Fig. 3i. Like the above observation at oil/brine interface, the small droplets formed at low-energy state facilitated stabilizing or bridging large oil droplets at high-energy state. High concentrations of $\mathrm{O}$ and $\mathrm{Fe}$ at the interface between a submicron droplet and a macroemulsion oil droplet (Fig. 3k, 1), further prove that PIONPs serve as bridges between submicron droplets, small droplets, and large droplets. Despite sparse interfacial coverage, our results demonstrate that hierarchy is achieved by a bridging mechanism where submicron droplets on the surface of small droplets in the contact region form a dense, bridging layer as a result of strong capillary attraction caused by the menisci around them.

\section{Effect of metal ions and oil polarity in the hierarchical stabilization mode}

The presence of calcium ions on the surface of submicron droplets (Extended Data Fig. 1i, Extended Data Fig. 4) and macroemulsion small and large droplets (Fig. 3m), suggests that these 
ions contribute to emulsion stability. To test this hypothesis, we used a porous microflow model connected with LSCM for the real-time observation of brine/oil/water interaction, and $\mathrm{Ca}^{2+}$ specific and $\mathrm{Na}^{+}$-specific fluorescence indicators of Fluo-3 and SBFI were used for detecting $\mathrm{Ca}^{2+}$ and $\mathrm{Na}^{+}$at the oil-water interface, respectively. As shown in LSCM images, a $\mathrm{Ca}^{2+}$-specific fluorescence signal is strongly correlated with the location of the nonpolar oil (1-octadecene)water interface (Fig. 4a), but the signal could not be detected at the interface between water and a more polar oil, here ethyl acetate (Fig. 4b). This is consistent with the observation that the submicron droplets $\left(0.1 \mathrm{wt} \%\right.$ PIONPs) in $0.4 \mathrm{M} \mathrm{CaCl}_{2}$ do not stabilize ethyl acetate macroemulsions, but stabilize nonpolar oil (e.g., toluene, decane, dodecane, or 1-octadecene) macroemulsions (Extended Data Fig. 9a, b). Moreover, the submicron droplets with very low (0.02 $w t \%)$ concentration of PIONPs were capable of stabilizing nonpolar oil macroemulsions only when the ionic strength of $\mathrm{CaCl}_{2}$ increases to $0.4 \mathrm{M}$ (Extended Data Fig. 9c). Although the nonpolar oil droplets of decane, dodecane, and 1-ocatadecene have different Ostwald ripening rates $^{22}$, they exhibit nearly similar size distribution and Sauter diameter in hierarchical stabilization mode (Extended Data Fig. 9d-f). Finally, the submicron droplets dispersed with $0.4 \mathrm{M}$ polyvalent ions such as $\mathrm{Ni}^{2+}, \mathrm{Co}^{2+}$ and $\mathrm{Fe}^{3+}$ also stabilized macroemulsions of nonpolar oil with similar size distribution and Sauter diameters (Extended Data Fig. 10a-i). In contrast, submicron droplets dispersed in $0.4 \mathrm{M} \mathrm{NaCl}$ failed to produce stable macroemulsions, and a $\mathrm{Na}^{+}$fluorescence signal was not detected in the microflow experiment (Extended Data Fig. 10a, j). Clearly, the interaction among polyvalent metal ions, oil/water interfaces, and PIONPs contributes to network formation and capillary forces between droplets and droplet aggregates, which arrest the Ostwald ripening from submicron to micron droplets.

\section{Effect of particle loading in the hierarchical stabilization mode}

As shown in photographs acquired 38 days after the preparation (Extended Data Fig. 11), most oilin-brine macroemulsions prepared by low (0.01-0.1 wt\%) concentration of PIONPs in the presence of $0.4 \mathrm{M} \mathrm{CaCl}_{2}$ showed significant coalescence, whereas oil-in-brine macroemulsions emulsified by submicron droplets with the same concentration of PIONPs showed stability. No coalescence and significant change in size distribution and Sauter diameter of oil droplets were apparent in macroemulsions prepared by submicron droplets even at very low (0.02-0.04 wt $\%)$ concentrations of PIONPs among 2, 11, and 38 days (Extended Data Fig. 12). This observation highlights that 
submicron droplets in brine are more effective, in terms of such low concentration of nanoparticles, at stabilizing macroemulsions than PIONPs dispersed in brine.

Optical micrographs and their droplet size distribution histograms reveal that at $0.15 \mathrm{wt} \%$ loading of PIONPs from submicron droplets, only non-aggregated and aggregated large droplets (5-20) $\mu \mathrm{m}$ are observed after 11 days' aging (Fig. 4c, Extended Data Fig. 13a), whereas the large droplets can coalesce into larger droplets $(20-100 \mu \mathrm{m})$ and more of the larger droplets form as particle loading decreases (Fig. 4d-g, Extended Data Fig. 13b-e). This means that the presence of submicron droplet stabilized small micron droplets can arrest the coalescence soon. Indeed, the surface coverage of large droplets by small droplets remained nearly the same as $21-26 \%$ between 0.04 and $0.1 \mathrm{wt} \%$ of PIONP loading (Fig. 4h, Fig. 3h, and Fig. 3j). This is following constant surface coverage model for Pickering emulsions (1) and means that the small $1.3 \mu \mathrm{m}$ droplets act as final stabilizers to share between large droplets and the coalesced droplets to form droplet aggregates, which leads to more efficient use of PIONPs and submicron droplets (Fig. 4i).

\section{Comparison of particle stabilizing efficiency in hierarchical and classic Pickering stabilization mode}

As explained above, the surface coverage of the submicron droplets (Fig. 4i, black symbol) reported here is comparable to many Pickering stabilizers (orange symbol), but the equivalent surface coverage by nanoparticles in hierarchically structured emulsions (green symbols) is an order of magnitude smaller. Moreover, the equivalent surface coverage decreases as the particle loading decreases. At $0.02 \mathrm{wt} \%$ particle loadings, the submicron droplet-stabilized droplets are 16 times smaller than the nominal Pickering-stabilized droplet. The multi-step emulsification and bridging effect produce a different scaling law between particle loading and droplet size. The black line in Fig. $4 \mathrm{j}$ is the result of using Eq (1) to predict Pickering behavior from the PIONP loading on the submicron droplets. The power-law exponent of -1 is observed for typical Pickering emulsions, orange symbols. In the hierarchical emulsions studied here nanoparticle loading (green symbols) and submicron droplet loading (magenta symbols) scales with the $-5 / 3$ power of droplet size, whereas small droplet loading (blue symbols) scales with the -1 power of droplet size. This further proves that the small droplets serve as final Pickering stabilizers for large oil droplets in macroemulsion. 
Our quantification of droplet surface coverage (Extended Data Tables 2-4), indicates that the ability of submicron droplets to bridge multiple small and large droplets underlies the greater efficiency. At particle loadings of $0.02-0.15 \mathrm{wt} \%$, the combined surface area of small and large droplets is 7 to 16 times greater than that of the Pickering stabilized submicron droplets, so that in effect the PIONPs are 8 to 17 times more efficient to stabilize an order of magnitude more droplet surface area at an effective coverage of $1.9 \%$ to $4.0 \%$. The lowest surface coverage at particle loadings of $0.02 \mathrm{wt} \%$ is nearly 3 times below the calculated minimal surface coverage of $5.5 \%$ required by the bridging mechanism of Pickering stabilization ${ }^{19}$. It is also 26 to 40 times less than that of the other reporting silica ${ }^{23}$ and polymer-coated silica ${ }^{24}$ nanoparticles for stabilizing macroemulsions by steric hindrance (Extended Data Table 5). The much lower surface coverage, whether calculated by submicron droplets or PIONPs, is thus a consequence of a novel mode of stabilization.

\section{Comparison of emulsion rheology in hierarchical, Pickering, and surfactant stabilization mode}

Amplitude sweep measurements demonstrate the strong dependency of macroemulsion viscoelastic signature on solution ionic strength and type and effective PIONP loadings (Extended Data Figs. 14-16). The maximum zero shear storage modulus $\left(\mathrm{G}_{0}{ }^{\prime}\right)$ and cross over frequency (indicating highest yield stress) were achieved at particle loadings of $0.04 \mathrm{wt} \%$ PIONPs in $0.4 \mathrm{M}$ $\mathrm{NiCl}_{2}$. Its $\mathrm{G}_{0}$ normalized by the Laplace pressure is 1.7 and 4.1 times larger than Pickering oil-inwater $\left(1.5 \mathrm{wt} \% \mathrm{SiO}_{2}, \sim 20 \mathrm{~nm}\right)$ and previously oil-in-brine emulsions $\left(1 \mathrm{wt} \% \mathrm{SiO}_{2}\right)^{25}$, respectively. It is also nearly 11 and 47 times more than surfactant stabilized oil-in-water emulsions with $2 \mathrm{wt} \%$ sodium dodecyl sulfate (SDS) and oil-in-brine emulsions ${ }^{26}$ with $1 \mathrm{wt} \%$ polyglycerol polyricinoleate (PGPR), respectively (Fig. 4k, Extended Data Fig. 17).

The creep/recovery signature of macroemulsions confirm these results (Extended Data Fig. 18, Fig. 41). During the creep stage, the $0.04 \mathrm{wt} \%$ particle loaded hierarchical emulsion in $0.4 \mathrm{M} \mathrm{NiCl}_{2}$ showed very strong deformability as the compliance of hierarchically structured emulsion only reached $0.005 \mathrm{~Pa}^{-1}$ at a shear $\left(3 \mathrm{~Pa}\right.$ ) of $300 \mathrm{~s}$, whereas $\mathrm{SiO}_{2}$ nanoparticle and SDS stabilized oil-inwater emulsions reached large compliance of 865 and $119 \mathrm{~Pa}^{-1}$, respectively. After the stress released in 300 to 900 s, the final recovery of the hierarchical emulsion is $62 \%$. In contrast, the surfactant stabilized emulsion only can instantaneously recover $15 \%$ and the Pickering emulsion 
nearly cannot be recovered due to its rigid interface and stiffness. These results mean that the viscoelastic properties of hierarchical emulsions can be tuned with polyvalent metal ions and particle concentrations to achieve higher strength and deformability, although the particle loadings are much lower than Pickering and surfactant stabilized emulsions.

\section{Conclusion}

Our results conclusively reveal a new hierarchical stabilization mechanism for emulsions. Unlike a Pickering emulsion generated from dispersed nanoparticles and stabilized exclusively via droplet armouring or bridging ${ }^{20,27}$, nanoparticles enter this system already attached to submicron droplets, where they remain during emulsion generation. The integral role of cations in these hierarchical structures also differs qualitatively from their usual influence on stabilization. Their contribution to particle/droplet attachment is independent of classical wettability-driven particle adhesion. This combined with the subsequent spontaneous formation of small droplets greatly enhances the particle's intrinsic interfacial activity, covered surface area, and roughness. This enables more stable macroemulsions formed at ultra-low particle loadings, for which stable Pickering emulsions would be impossible, thereby reducing the amount, cost, and environmental impact of emulsifiers in industrial applications. Moreover, the novel hierarchically structured emulsion integrates the advantages of Pickering and surfactant stabilized emulsions. Due to its ultra-low nanoparticle loadings, this kind of emulsion realizes better control of microstructure and simultaneously achieves high connectivity, deformability and strength. This in turn enables templated synthesis of highly permeable macroporous materials for drug delivery, enhanced in situ or in vivo imaging, and catalysis.

Data availability The data analysed or generated in this study are included in this published article (and its supplementary Figures and Tables).

Code availability No code is used in this study. 


\section{References:}

1. Ramsden, W. Separation of solids in the surface-layers of solutions and 'suspensions' (observations on surface-membranes, bubbles, emulsions, and mechanical coagulation). Preliminary account. Proc. R. Soc. London 72, 156-164 (1903).

2. Pickering, S. U. CXCVI.-Emulsions. J. Chem. Soc. Trans. 91, 2001-2021 (1907).

3. Binks, B. P. Colloidal particles at a range of fluid-fluid interfaces. Langmuir 33, 6947-6963 (2017).

4. Binks, B. P. \& Horozov T. S. Eds., Colloidal Particles at Liquid Interfaces. Cambridge University Press (2006).

5. Richtering, W. Responsive emulsions stabilized by stimuli-sensitive microgels: emulsions with special non-Pickering properties. Langmuir 28, 17218-17229 (2012).

6. Ikem, V. O., Menner, A., Horozov, T. S., \& Bismarck, A. Highly permeable macroporous polymers synthesized from pickering medium and high internal phase emulsion templates. Advanced Materials 22, 3588-3592 (2010).

7. Kataruka, A. \& Hutchens, S. B. PDMS polymerized high internal phase emulsions (polyHIPEs) with closed-cell, aqueous-filled microcavities. Soft matter, 15, 9665-9675 (2019).

8. Fratzl, P. \& Weinkamer, R. Nature's hierarchical materials. Prog. Mater. Sci. 52, 1263-1334 (2007).

9. Thompson, B. R., Horozov, T. S., Stoyanov, S. D. \& Paunov, V. N. Hierarchically structured composites and porous materials from soft templates: fabrication and applications. J. Mater. Chem. A 7, 8030-8049 (2019).

10. Jia, H. et al. Hierarchical porous silicon structures with extraordinary mechanical strength as high-performance lithium-ion battery anodes. Nat. Commun. 11, 1-9 (2020).

11. Zhu, Y., Wang, W., Yu, H. \& Wang, A. Preparation of porous adsorbent via Pickering emulsion template for water treatment: A review. J. Environ. Sci. 88, 217-236 (2020).

12. Wu, J., \& Ma, G. H. Recent studies of Pickering emulsions: particles make the difference. Small 12, 4633-4648 (2016). 
13. Sun, Y., Zhu, Y., Zhang, S. \& Binks, B. P. Fabrication of hierarchical macroporous ZIF-8 monoliths using high internal phase Pickering emulsion templates. Langmuir, 37, 8435-8444 (2021).

14. Akartuna, I., Studart, A. R., Tervoort, E. \& Gauckler, L. J. Macroporous ceramics from particle-stabilized emulsions. Advanced Materials, 20(24), 4714-4718 (2008)..

15. Jiao, B., Shi, A., Wang, Q., \& Binks, B. P. High-internal-phase pickering emulsions stabilized solely by peanut-protein-isolate microgel particles with multiple potential applications. Angewandte Chemie, 130, 9418-9422 (2018).

16. Binks, B. P. \& Lumsdon, S. O. Pickering emulsions stabilized by monodisperse latex particles: effects of particle size. Langmuir 17, 4540-4547(2001).

17. Chevalier, Y. \& Bolzinger, M. Emulsions stabilized with solid nanoparticles: Pickering emulsions. Colloids Surf. A 439, 23-34 (2013).

18. Low, L. E., Siva, S. P., Ho, Y. K., Chan, E. S. \& Tey, B. T. Recent advances of characterization techniques for the formation, physical properties and stability of Pickering emulsion. $A d v$. Colloid Interface. Sci. 277, 102117 (2020).

19. Vignati, E., Piazza, R. \& Lockhart, T. P. Pickering emulsions: Interfacial tension, colloidal layer morphology, and trapped-particle motion. Langmuir 19, 6650-6656 (2003).

20. Bizmark, N. \& Ioannidis, M. A. Nanoparticle-stabilised emulsions: droplet armouring vs. droplet bridging. Soft Matter. 14, 6404-6408 (2018).

21. Arismendi-Arrieta, D. J. \& Moreno A. J. Deformability and solvent penetration in soft nanoparticles at liquid-liquid interfaces. J. Colloid Interface Sci. 570, 212-222 (2020).

22. Taylor, P. Ostwald ripening in emulsions: estimation of solution thermodynamics of the disperse phase. Adv. Colloid Interface Sci. 106, 261-285 (2003).

23. Derakhshandeh, M., Pilapil, B. K., Workman, B., Trifkovic, M. \& Bryant, S. L. Analysis of network formation and long-term stability in silica nanoparticle stabilized emulsions. Soft Matter. 14, 4268-4277 (2018).

24. Zhang, T. Emulsions stabilized with nanoparticles for potential conformance control applications, thesis, University of Texas at Austin, Austin, TX (2009). 
25. Griffith, C. \& Daigle, H. Manipulation of Pickering emulsion rheology using hydrophilically modified silica nanoparticles in brine. J. Colloid Interface Sci. 509, 132-139 (2018).

26. Márquez, A. L., Medrano, A., Panizzolo, L. A. \& Wagner, J. R. Effect of calcium salts and surfactant concentration on the stability of water-in-oil (w/o) emulsions prepared with polyglycerol polyricinoleate. J. Colloid Interface Sci. 341, 101-108 (2010).

27. Horozov, T. S. \& Binks, B. P. Particle-stabilized emulsions: a bilayer or a bridging? Angewandte Chemie 45, 773-776 (2006). 


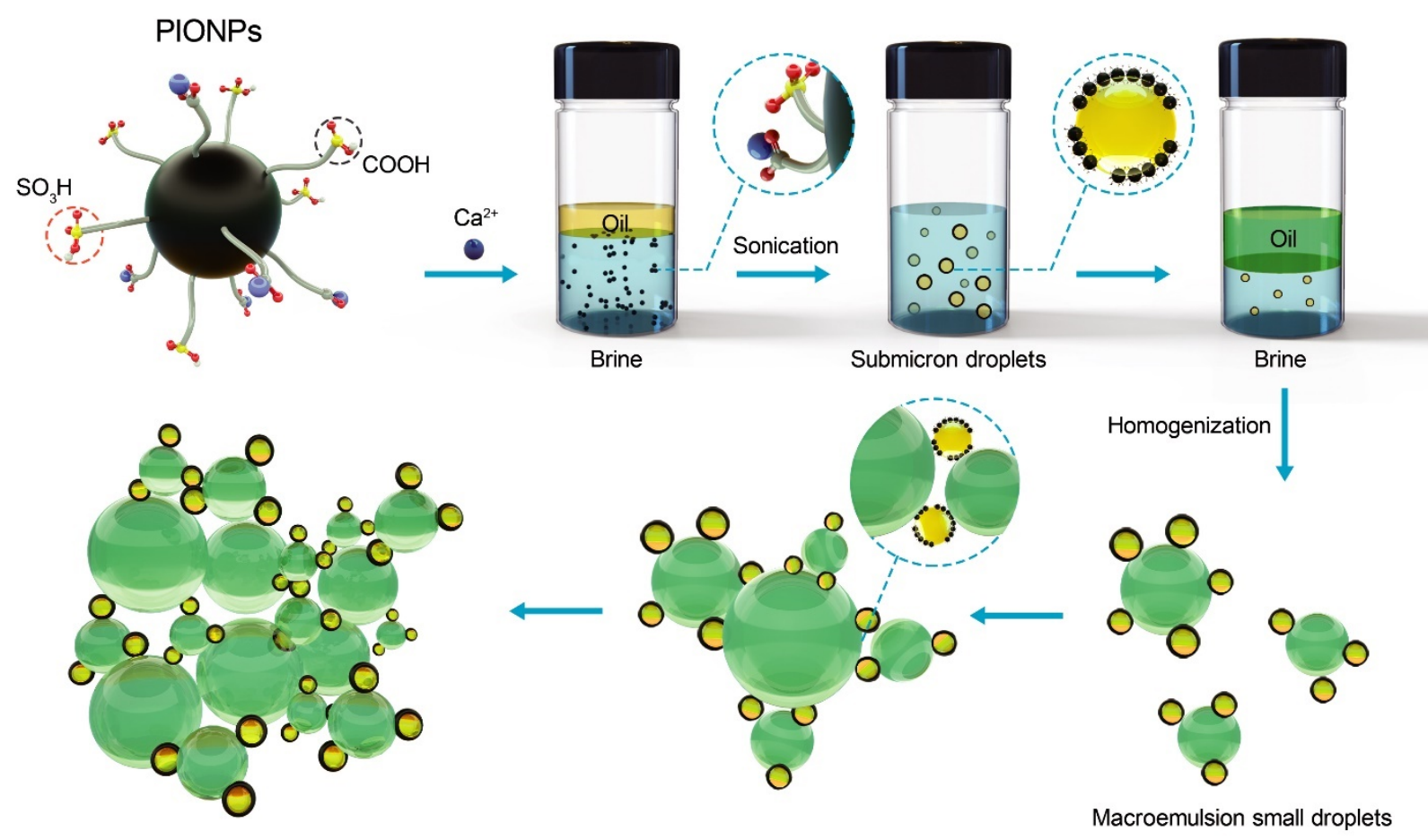

Fig. 1| Schematic of fabricating hierarchically structured emulsions. First level is stabilization of submicron droplets (yellow spheres) ca. $250 \mathrm{~nm}$ in diameter by PIONPs (black spheres) ca. 25 $\mathrm{nm}$ in diameter and polyvalent cations. In the second level, submicron droplets dispersed in brine attach to small droplets of oil (green spheres, bottom right) ca. $1.3 \mu \mathrm{m}$ in diameter, which in turn attach to large droplets (green spheres, bottom middle) 5 to $50 \mu \mathrm{m}$ in diameter. Finally, the small droplets bridge large droplets to yield a gel-like structure (droplet aggregates) that stabilizes the macroemulsion at low overall concentration of PIONPs (bottom left). 


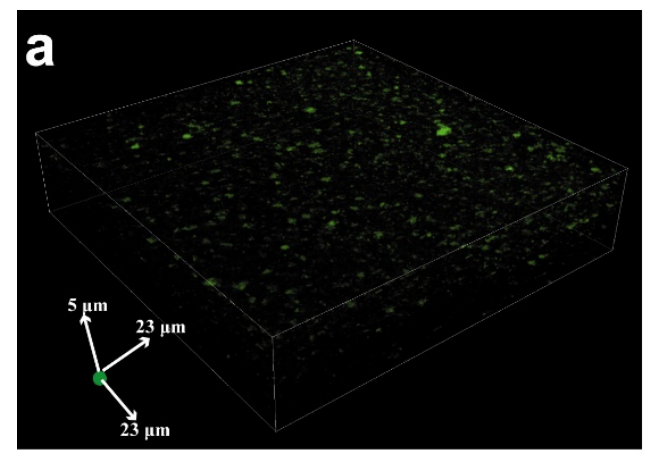

3-D LSCM

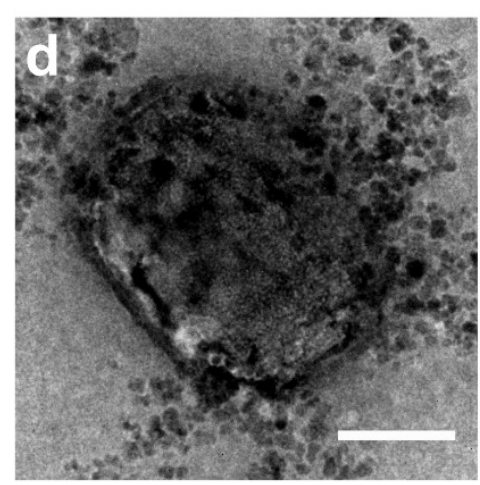

Liquid TEM

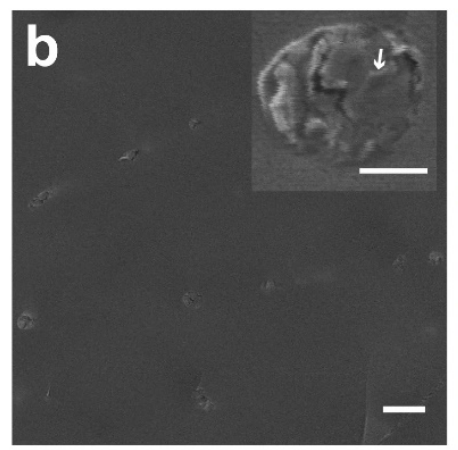

Cryo-SEM

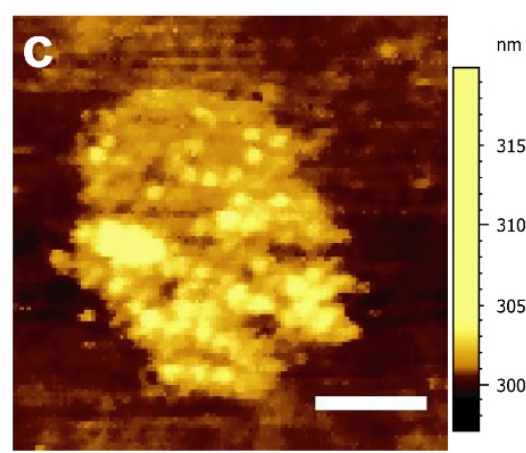

AFM

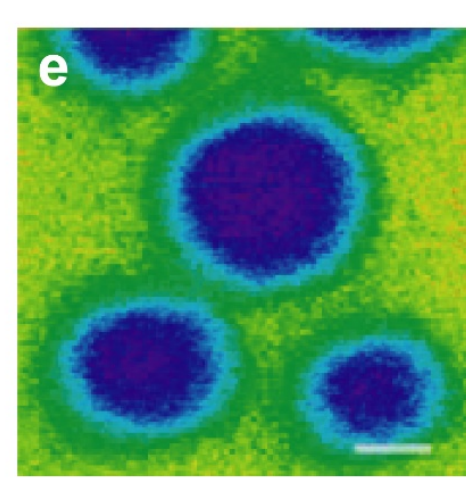

O-edge STXM
0.77

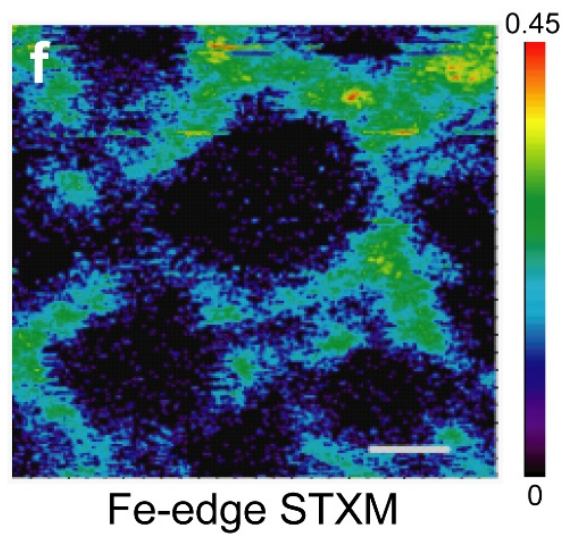

Fig. 2| Structural characterization of submicron droplets. a, 3-D LSCM image demonstrating that oil (1-octadecene) submicron droplets (green) are uniformly distributed through the aqueous phase (unlabeled). b, Cryo-SEM image (scale bar, $1 \mathrm{~mm}$ ). Inset (scale bar, $200 \mathrm{~nm}$ ) reveals PIONPs on a single droplet (white arrow). $\mathbf{c}, \mathbf{d}, \operatorname{AFM}(\mathbf{c})$ and TEM (d) of single submicron droplet captured in a liquid cell shows partial surface coverage by clusters of PIONPs (AFM: white dots, TEM: black dots). e, STXM oxygen map establishes location of oil-water interface for several submicron droplets, at which (f) iron map confirms the presence of PIONPs. Scale bars in $\mathbf{c}-\mathbf{f}$ : $200 \mathrm{~nm}$. 


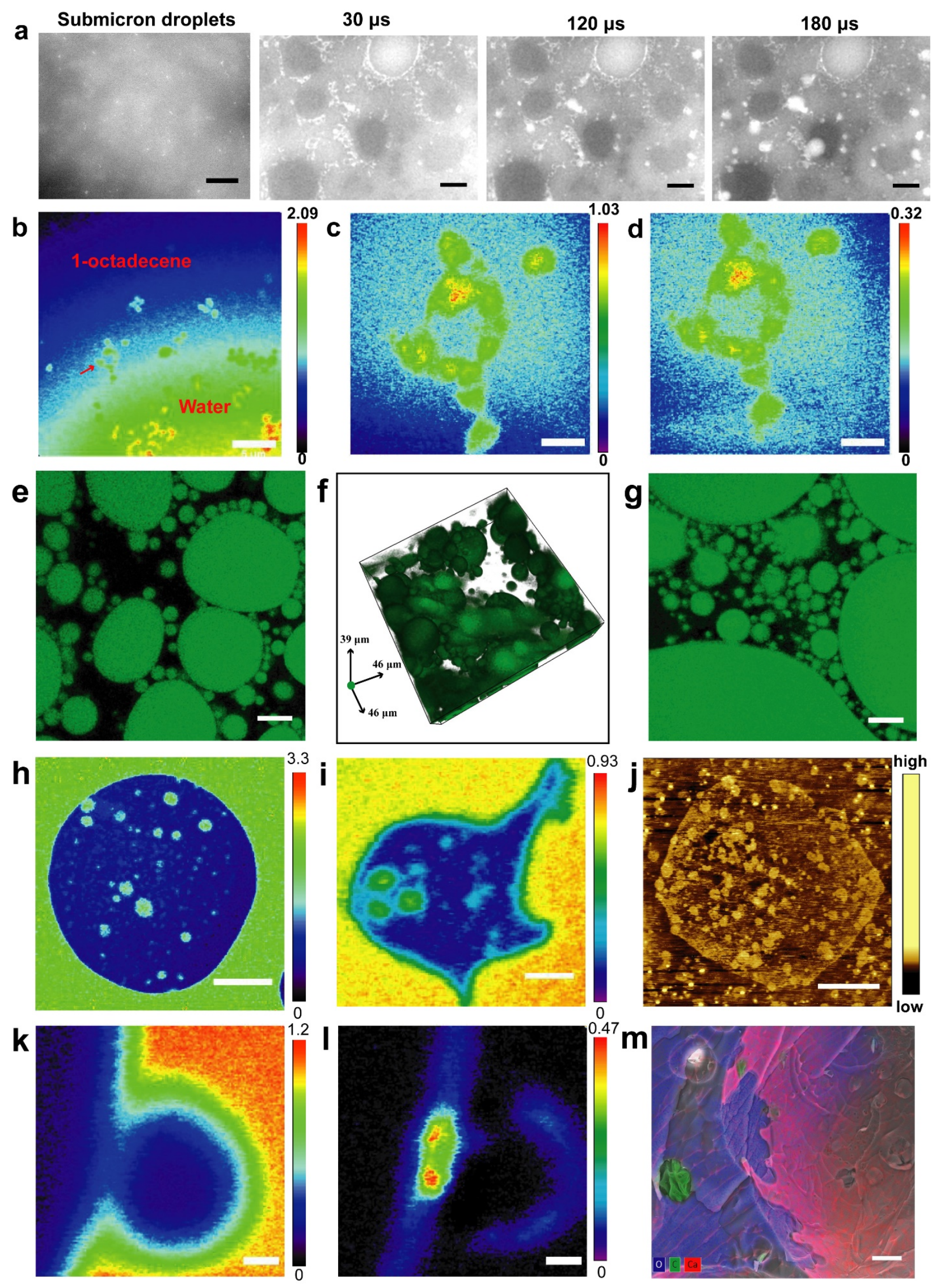


Fig. 3| Hierarchical stabilization of macroemulsion by submicron droplets at low concentration (0.1 wt\%) of PIONPs. a, Time series images of submicron droplets before and after reacting with 1-octadecene imaged in brine by liquid cell SEM (scale bars, $1 \mu \mathrm{m}$ ). b, STXM oxygen map at the 1-ocatadecene-brine interface. c, d, Magnified oxygen (c) and iron (d) maps of a micrometer-sized structure (red arrow in b) assembled by submicron droplets. e-g, Hierarchical structure at scale of large droplets revealed by LSCM: (e) 2-D slice, (f) 3-D volume and (g) 2-D slice. Oil phase is labeled green; scale bars, $5 \mu \mathrm{m}$. h-j. Hierarchical structure at smaller scales revealed by: STXM oxygen map (h) of a large droplet (scale bar, $5 \mu \mathrm{m}$ ) shows small droplets on its surface; submicron droplets are evident as rough edges of small droplets; STXM oxygen map (i) of a small droplet shows submicron droplets on its surface (scale bar, $500 \mathrm{~nm}$ ); AFM image (j) of a large droplet shows small droplets, whose irregular surfaces are consistent with attached submicron droplets (scale bar, $5 \mu \mathrm{m}$ ). $\mathbf{k}, \mathbf{l}$, The interface between a submicron droplet and a large droplet imaged by STXM Oxygen (k), and iron (l) maps (scale bars, $100 \mathrm{~nm}$ ). m, Cryo-SEM image of calcium ions at the macroemulsion interface (scale bar, $5 \mu \mathrm{m}$ ). 


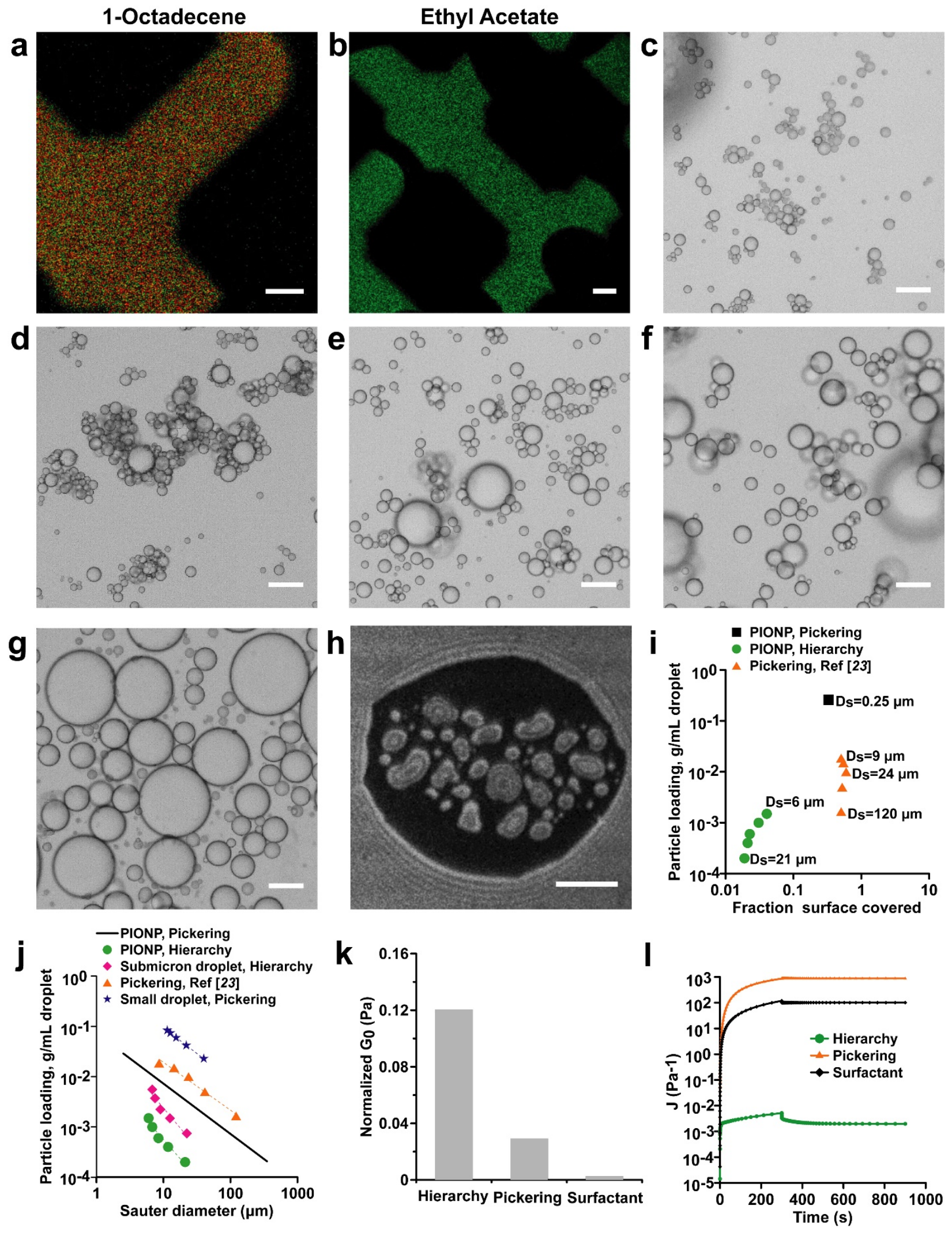

Fig. 4| Effect of metal ions, oil polarity and particle loading in hierarchical stabilization mode. 
a, b, LSCM images (scale bars, $20 \mu \mathrm{m}$ ) of calcium ions (red) interacting with the oil (green) of nonpolar 1-octadecene (a) and more polar ethyl acetate (b). c-g, Optical microscope images (scale bars, $50 \mu \mathrm{m})$ of 1-octadecene macroemulsions prepared by submicron droplets with PIONP loading of $0.15 \mathrm{wt}^{\mathrm{O}} \%$ (c), $0.10 \mathrm{wt} \%$ (d), $0.06 \mathrm{wt} \%$ (e), $0.04 \mathrm{wt} \%$ (f) and $0.02 \mathrm{wt} \%$ (g). h, LSCM image (scale bar, $2 \mu \mathrm{m}$ ) of a macroemulsion large droplet with very low PIONP loadings of 0.04 $\mathrm{wt} \%$. i, Comparison of particle stabilizing efficiency in hierarchical and Pickering stabilization mode $\left(D_{s}\right.$, Sauter diameter). j, Different power law scaling (dotted line) between particle loading and droplet size in hierarchical and Pickering stabilization mode. The data of typical silicastabilized Pickering emulsions (orange triangle) are calculated from ref. ${ }^{23}$. k, Comparison of elasticity for hierarchical, Pickering and surfactant stabilized oil-in-brine emulsions. The $\mathrm{G}_{0}$ is nomalized by Laplace pressure, the ratio of the oil-water interfacial tension to the Sauter diameter. The data of Pickering emulsions in $1 \mathrm{wt} \% \mathrm{CaCl}_{2}$ are calculated from $1 \mathrm{wt} \%$ silica nanoparticles with high surface concentration of hydrophilic polymers, ref. ${ }^{25}$. The data of surfactant stabilized emulsions ( $1 \mathrm{wt} \%$ PGPR) in $0.25 \mathrm{M} \mathrm{CaCl}_{2}$ are calculated from ref. ${ }^{26} . \mathbf{1}$, Compliance versus time in creep and recovery test for hierarchical, Pickering and surfactant emulsions. 


\section{Methods}

\section{Synthesis of polymer-coated iron oxide nanoparticles}

The monodispersed PIONPs were synthesized by sonicating polymer of poly (4styrenesulfonic acid-co-maleic acid) sodium salt (20 kD, Sigma-Aldrich) and iron oxide $\left(\mathrm{Fe}_{3} \mathrm{O}_{4}\right)$ nanoparticles (US Research Nanomaterials, Inc.). A total of $300 \mathrm{~mL}$ of MiliQ water was poured into a $400 \mathrm{~mL}$ clean beaker, and $12 \mathrm{~g}$ polymer was dissolved in water. The $\mathrm{pH}$ of the polymer solution was adjusted to 5 by adding concentrated $\mathrm{HCl}$. Then, $3 \mathrm{~g}$ of iron oxide nanoparticles were added in solution followed by ultrasonication for $60 \mathrm{~min}$ at $50 \%$ amplitude in an ice bath. To remove non-coated nanoparticles, after sonication, the solution was centrifuged for 20 min at 4,000 g. Finally, the supernatant was processed by five steps of concentrating and washing with DI water using $100 \mathrm{kD}$ centrifugal filter units (Amicon®Ultra-12, $100 \mathrm{kDa}$ ) to remove free polymers. After several centrifuging steps, the PIONPs yield ranged from $20 \%$ to $30 \%$.

\section{Structural characterization of PIONPs}

The iron oxide content of PIONPs were determined using an inductively coupled optical emission spectrometer (ICP-OES, Avio 200 ICP Optical Emission Spectrometer, PerkinElmer) to measure Fe content in the core. For the ICP-OES measurement, the Fe standard sample was diluted to $0,1,2,4,8$, and $10 \mathrm{ppm}$, and the PIONPs were dissolved by $5 \mathrm{v} / \mathrm{v} \%$ hydrochloric acid and diluted to the concentration lower than $10 \mathrm{ppm}$ before measurement. The weight of polymer shell was determined by the whole dry weight of sample minus the weight of $\mathrm{Fe}_{3} \mathrm{O}_{4}$ core. The weight ratio of iron oxide to polymer is approximately $1: 4$.

The core size and shape of PIONPs were imaged using a transmission electron microscopy (TEM, JEOL JEM-2100, Japan) instrument with a $200 \mathrm{keV}$ acceleration voltage and the whole particle size and shape were imaged by a scanning electron microscopy (Zeiss Auriga Compact FIB-SEM) with a $5 \mathrm{KeV}$ acceleration voltage. A dilute aqueous solution of PIONPs was deposited onto an ultrathin carbon-coated copper grid (200 mesh). The size distribution was determined by the Image J analysis of more than 800 particles.

The colloidal stability was tested by dynamic light scattering (DLS) and zeta potential measurements at room temperature $\left(25^{\circ} \mathrm{C}\right)$ using a DynaPro NanoStar instrument (Wyatt 
Technology Corporation. USA) and a Malvern Zetasizer Nano ZSP instrument. To evaluate the colloidal stability of PIONPs, the stock solutions of $5 \mathrm{M} \mathrm{CaCl}_{2}$ and PIONPs were diluted to achieve a concentration of $0.1 \mathrm{wt} \%$ PIONPs in $0-1 \mathrm{M} \mathrm{CaCl}_{2}$, and the particle sizes in water and brine were determined in the intensity-weighted mode.

The FTIR spectra of polymers at $\mathrm{CaCl}_{2}$ were obtained with a Bruker Vertex $70 \mathrm{v}$ spectrometer. $4 \mathrm{wt} \%$ polymers were placed in water or brine $\left(0.4 \mathrm{M} \mathrm{CaCl}_{2}\right)$ for 24 hours. Then these samples were frozen-dried and added to a pressed $\mathrm{KBr}$ disk to form a thin film. The disk was quickly placed into the sample chamber for FTIR analysis with a $2 \mathrm{~cm}^{-1}$ resolution in the spectral range of 400$4000 \mathrm{~cm}^{-1}$. The FTIR spectra were collected using an average of 300 scans. The system was rapidly evacuated, and a background spectrum of the $\mathrm{KBr}$ disc without a sample was collected under the same instrumental conditions. All spectra were corrected for the background.

\section{Synthesis and colloidal stability of submicron droplets}

Oil-in-brine submicron droplets were synthesized using a 3:17 oil:brine volume ratio. The concentrated brine solution of $5 \mathrm{M} \mathrm{CaCl}_{2}$ was first prepared in a $50 \mathrm{~mL}$ plastic tube. Then, the concentrated brine was mixed with an aqueous solution of PIONPs to achieve $5.10 \mathrm{wt} \%$ in $0.4 \mathrm{M}$ $\mathrm{CaCl}_{2}$ and $3 \mathrm{~mL}$ of 1 -octadecene in a vial for sonication (30s/30s, $50 \%$ amplitude) of $10 \mathrm{~min}$ in an ice bath. The solution was kept at room temperature for $24 \mathrm{~h}$ to observe the absence of separated layers and confirm that uniform nanodroplets were successfully synthesized. The nanoparticle content of submicron droplets was determined using ICP-OES. The colloidal stability of submicron droplets in $0.4 \mathrm{M} \mathrm{CaCl}_{2}$ was evaluated by DLS measurements of their hydrodynamic sizes $\left(\mathrm{D}_{\mathrm{H} S}\right)$ after settling for 7,22 , and 35 days at $25^{\circ} \mathrm{C}$.

\section{Hydrophilicity characterization of PIONPs, calcium ion bound PIONPs and submicron droplets}

The hydrophilicity of glass cover slips covered with PIONPs, calcium ion bound PIONPs and submicron droplets were performed by a data physics optical contact angle measuring system

(OCA 15EC). The $\mathrm{Ca}^{2+}$ bound PIONPs were prepared by incubation PIONPs in $0.4 \mathrm{M} \mathrm{CaCl}_{2}$ for $24 \mathrm{~h}$ and then dialyzed in 1000 times volume of deionized water to remove calcium ions. The submicron droplets were also dialyzed in deionized water to remove calcium ions after preparation. Then the concentrated PIONPs, $\mathrm{Ca}^{2+}$ bound PIONPs, and submicron droplets were added to form 
flat films on the cover slips. A $5 \mu \mathrm{L}$ drop of water was added on each cover slip, and the contact angle was recorded quickly in 5 miniutes by the contact angle measuring system.

\section{Preparation of oil-in-brine macroemulsions}

For comparison stabilizing efficiency of PIONPs and submicron droplets, oil-in-brine $(10 \mathrm{~mL}$ of each phase) macroemulsions were synthesized by mixing 1-octadecene, $0.4 \mathrm{M} \mathrm{CaCl}_{2}$, and submicron droplets or PIONPs at concentrations between 0.01 and $0.10 \mathrm{wt} \%$. The homogenizer was tuned to medium strength for 2 min to ensure complete mixing and these macroemulsions were placed at room temperature for 38 days. For evaluate metal ions' effect in hierarchical stabilization mode, monovalent and multivalent metal ions, such as $\mathrm{Na}^{+}(0.4 \mathrm{M} \mathrm{NaCl}), \mathrm{Ca}^{2+}(0.4 \mathrm{M}$ $\left.\mathrm{CaCl}_{2}\right), \mathrm{Co}^{2+}\left(0.4 \mathrm{M} \mathrm{CoCl}_{2}\right), \mathrm{Ni}^{2+}\left(0.4 \mathrm{M} \mathrm{NiCl}_{2}\right)$, and $\mathrm{Fe}^{3+}\left(0.4 \mathrm{M} \mathrm{FeCl}_{3}\right)$, were used to prepare oilin-brine $(5 \mathrm{~mL}$ of each phase) macroemulsions by mixing with submicron droplets $(0.04 \mathrm{wt} \%$ PIONPs) and 1-octadecene oil. To study particle loading effect in hierarchical stabilization mode, a series of oil-in-brine ( $5 \mathrm{~mL}$ of each phase) macroemulsions were prepared by mixing 1octadecene, $0.4 \mathrm{M} \mathrm{CaCl}_{2}$, and submicron droplets with PIONP loadings between 0.01 and 0.15 $\mathrm{wt} \%$. The digital and microscope images of emulsions were taken after preparation of 2, 11 and 38 days.

\section{Stability of macroemulsions}

The stability of macroemulsions was evaluated by visual and microscope observation and rheology measurements. The visual observation of macroemulsions was recorded during $38 \mathrm{~d}$ settling at room temperature, and the destabilization of the emulsion was evaluated by change of color. Once nanoparticles were detached from the oil-water interface and droplets of the oil phase were broken, the upper layer of oil could be observed and the color would become much more yellow-brown. An Olympus upright microscope (Olympus BX-51) was used to capture optical micrographs of macroemulsion oil large droplets. To ensure the structural integrity of the droplets and ensure accurate size analysis, each macroemulsion was loaded into a bacterium counting plate composed of a liquid cell separated by a slide and a cover glass. About 300-500 droplets of each macroemulsion were analyzed in ImageJ software for size analysis. The Sauter average droplet diameter, $D_{32}$, can be acquired as the sum of all the oil droplets in the emulsion: 
$D_{32}=\sum_{i} D_{i}^{3} \times N_{i} / \sum_{i} D_{i}^{2} \times N_{i}$

where $D_{\mathrm{i}}$ is the measured droplet diameter and $N_{\mathrm{i}}$ is the number of droplets.

An oscillatory rheometer (Anton Paar MCR-302) was used to determine the rheological characteristics of the macroemulsion at ambient temperature using sandblasted parallel plate geometry ( $25 \mathrm{~mm}$ in dimeter). The rheological measurements were conducted at a gap size of 1 $\mathrm{mm}$ and the amplitude sweep experiments (shear strain of 0.1-1000\%) were performed at a frequency of $1 \mathrm{~Hz}$ to determine the linear viscoelastic (LVE) range. For creep-recovery test, a constant stress amplitude of $3 \mathrm{~Pa}$ was applied instantly and maintained for a period of $300 \mathrm{~s}$, then the stress was released and the compliance was recorded during $900 \mathrm{~s}$. Finally, calculation of the final percentage recovery was in accordance with the following equation:

$$
\% \text { Recovery }=\left[\frac{\left(J_{M A X}-J_{\infty}\right)}{J_{M A X}}\right] \times 100
$$

Where $J_{M A X}$ is the compliance of the system reached maximum deformation, $J_{\infty}$ is the compliance values at $600 \mathrm{~s}$ after the stress released.

\section{Cryo-SEM imaging}

The oil-water interfacial activities of PIONPs and submicron droplets were characterized by an environmental field emission SEM (Quanta ${ }^{\mathrm{TM}} 250 \mathrm{FEG}$ ) under the cryo-state. A small volume of submicron droplets after dialysis or freshly prepared macroemulsions was put into a rivet and quickly frozen in a nitrogen slush. When the samples were loaded into the SEM chamber, a thin layer of sputtered gold was deposited, and the images were acquired either by secondary electron or backscattered electron detectors at a $5 \mathrm{kV}$ accelerating voltage to detect nanoparticles or submicron droplets at the oil-water interface. The energy-dispersive X-ray spectroscopy analysis was conducted after the overall workflow and optimization of the accelerating voltage.

\section{Liquid cell AFM imaging}

AFM (Keysight 5500 scanning probe microscope system) conducted in contact mode was used to scan the 3-D topography of submicron droplets and macroemulsion oil droplets. The specimen was prepared by adding $100 \mu \mathrm{L}$ submicron droplets or macroemulsion droplets on a 
cover glass and placed in a moist atmosphere for $10 \mathrm{~min}$. Then, the cover glass was rinsed off with DI water to remove these droplets that did not adhere to the glass, quickly put in a liquid plastic cell, and secured with adhesive tape. A scanner carrying a long rectangular cantilever (PPP-CONT50 , NanoAndMore USA Corp.) with a spring constant of $0.2 \mathrm{~N} / \mathrm{m}$ was placed above the specimen. The scanning was conducted in DI water with a scanning rate of $0.5 \mathrm{~Hz}$ with a resolution of $512 \times$ 512 pixels. The acquired AFM images were processed by supplied software to create 3D topographic images and calculate surface roughness.

\section{Liquid cell TEM imaging}

A TEM (JEOL JEM-2100) was used to characterize the microstructure of submicron droplet in liquid using a microfluidic sample chamber (In situ Technology), which is constituted by two ultrathin $(\sim 20 \mathrm{~nm})$ electron translucent $\mathrm{SiN}_{\mathrm{x}}$ membranes separated by $\sim 100 \mathrm{~nm}$ with spacers. A total of $1 \mu \mathrm{L}$ of submicron droplet solution was added to one end of the chip and pumped through a syringe to allow droplets to enter the chip chamber. Finally, the chip was installed on the conventional electron microscope rod, and imaging was conducted with a low voltage of $120 \mathrm{kV}$ to prevent submicron droplets from electron damage.

\section{Liquid cell STXM imaging}

The STXM measurements of submicron droplets, submicron droplet at the oil-water interface, and macroemulsions were conducted at the SM (10ID-1) beamline of the Canadian Light Source using soft X-rays generated from the $2.9 \mathrm{GeV}$ synchrotron storage ring. A fully hydrated sample of submicron droplets or macroemulsions was prepared as a thin layer in a wet specimen cell that comprised two ultrathin $(\sim 100 \mathrm{~nm})$ silicon nitride windows. The wet cell was sealed with epoxy glue, which prevented the sample from drying out. The oxygen map was directly obtained by STXM at the photon energy of $540 \mathrm{eV}$. The iron-edge STXM imaging was acquired from strong and weak absorption of $\mathrm{Fe}$ at the photon energies of 710 and $700 \mathrm{eV}$, respectively. Then, the Xray absorption map of $\mathrm{Fe}$ was calculated from the $710 \mathrm{eV}$ image subtracted by the $700 \mathrm{eV}$ image after both images were converted to optical density (absorption) beforehand. To acquire the interfacial structure between a submicron droplet and a macroemulsion large droplet of oil phase, O-, Fe-, and benzene-edge STXM imaging was conducted in the same region. The benzene-edge map was acquired from strong and weak absorption of benzene at the photon energies of 285.2 
and $282 \mathrm{eV}$. The dynamic submicron droplet/oil/brine interaction was monitored by STXM after loading submicron droplets $\left(0.10 \mathrm{wt} \%\right.$ PIONPs in $\left.0.4 \mathrm{M} \mathrm{CaCl}_{2}\right)$ and 1-octadecene into the wet cell for $2 \mathrm{~h}$. The oxygen and iron map were directly imaged at the photon energy of 540 and $710 \mathrm{eV}$.

\section{In situ LSCM imaging}

A Leica SP8 inverted LSCM instrument operated by the LASX software was used to image submicron droplets and macroemulsions in original state ${ }^{28}$. To acquire two-dimensional (2-D) LSCM images, the oil of 1-octadecene was tagged with perylene dye $(0.01 \mathrm{mg} / \mathrm{mL})$. Submicron droplets and macroemulsions were placed in a tight space separated by a slide and a cover glass so that both oil and water phases could be observed by fluorescence microscopy. To obtain threedimensional (3-D) LSCM images, the 2-D time stacks (videos) were recorded at the frame rate of 50 frames per second. The 3-D reconstruction and image processing of $\mathrm{z}$ stacks were conducted using the Avizo software (Version 9.0.1, CMC microsystems). The 2-D and 3-D images were processed to measure emulsion droplet size by the ImageJ software.

A porous microflow model connected with LSCM was used for the real-time monitoring of dynamic submicron droplet/oil/brine and brine/oil/water interactions. The microflow model was constituted by a Micronit borosilicate glass with uniform microfluidic networks (45.0 mm $\times 15.0 \mathrm{~mm}$ chip size, $50.0 \mu \mathrm{m}$ channel width, and $20.0 \mu \mathrm{m}$ channel depth). For the realtime observation of PND/oil/brine interactions, microfluidic network flooding was sequentially conducted using the following steps: saturating networks with brine by injecting a $0.4 \mathrm{M} \mathrm{CaCl}_{2}$ aqueous solution into the channels at $5 \mu \mathrm{L} / \mathrm{min}$, establishing an oil/brine interface through 1octadecene oil injection until no more brine water was produced, acquiring residual oil/brine by further brine flooding until no more oil was produced, and submicron droplet flooding. The oil was tagged with oil-blue (green), and PND was labeled with perylene (red), which allowed realtime fluorescence imaging of submicron droplet/oil/brine interactions. To probe the $\mathrm{Ca}^{2+} / \mathrm{oil} /$ water interaction, several residual oil/water interfaces were formed in the microfluidics after saturation with DI water and nonpolar oil of 1-octadecene or more polar oil of ethyl acetate, followed by oil displacement by water. Then, one pore volume of $0.4 \mathrm{M} \mathrm{CaCl}_{2}$ was slowly injected into the microfluidic network at $5 \mu \mathrm{L} / \mathrm{min}$. After three times of repeated washing of non-absorbed $\mathrm{Ca}^{2+}$ with DI water, a calcium ion-specific fluorescence indicator of Fluo-3 was used to detect whether there were calcium ions at the oil-water interface. To probe $\mathrm{Na}^{+} /$oil/water interaction, a fluorescent 
indicator of SBFI was used to specifically detect sodium ions at the oil-water interface in the microfluidic channels.

\section{In situ liquid cell SEM imaging}

An environmental field emission SEM (Quanta ${ }^{\mathrm{TM}} 250 \mathrm{FEG}$ ) operated at $20 \mathrm{kV}$ was used for the in situ imaging of PND/brine/oil interactions. The in situ technology was achieved through a microfluidic liquid cell (FlowView Aquarius) constituted by an ultrathin $(\sim 20 \mathrm{~nm})$ electron translucent $\mathrm{SiN}_{\mathrm{x}}$ membrane and a solid microchannel substrate separated by $\sim 500 \mathrm{~nm}$ with spacers. A total of $0.5 \mu \mathrm{L}$ of 1 -octadecene oil was loaded into the solid microchannel substrate, and the oil was left for $2 \mathrm{~min}$ to allow the oil to slowly diffuse into droplets and adhere to the substrate. Then, $0.5 \mu \mathrm{L}$ of submicron droplets $(0.10 \mathrm{wt} \%)$ in brine solution was added, and the cell was quickly closed with a translucent $\mathrm{SiN}_{\mathrm{x}}$ membrane. The SEM images were obtained at the rate of one frame per $30 \mu \mathrm{s}$ immediately after the sample was inserted into the SEM chamber and focused on by the Everhart-Thornley detector.

\section{Quantification of PIONP surface coverage on submicron droplets}

The quantification of surface coverage on submicron droplets carried according to Dr. Tiantian Zhang's master thesis ${ }^{24}$. It was assumed that all the droplets formed are spherical, and the quantity of each component in the mixture before and after sonication/homogenization should be conserved, neglecting the loss of experimental observation. The total interfacial area of the submicron droplets was calculated using the data from emulsion droplet size analysis through dynamic light scattering. As the median radius of submicron droplets $\left(R_{s m d}\right)$ was calculated through intensity-weighted $\mathrm{D}_{\mathrm{HS}}$, then the total interfacial area of submicron droplets is

$A_{t}=N_{s m d} \overline{A_{\text {smd }}}$

where $N_{s m d}$ is the number of submicron droplets in the emulsions and $\overline{A_{s m d}}=4 \pi<R_{s m d}^{2}>$ is the average interfacial area. After obtaining the total interfacial area, we calculated the fraction of the total submicron droplet interfacial area covered by PIONPs. The initial mass $\left(M_{i}\right)$ and average radius $\left(R_{p}\right)$ of nanoparticles in the mixture were known. The density $(\rho)$ of PIONPs could be 
calculated as $2206 \mathrm{Kg} / \mathrm{m}^{3}$ through ICP-OES analysis of Fe content in the core and polymer to iron oxide weight ratio, then the number of nanoparticles is

$N_{p}=M_{i} / \rho \overline{V_{p}}$

where $\overline{V_{p}}$ is the average volume of nanoparticles. Then the fraction of submicron droplet surface covered with nanoparticles is

$f_{s p}=N_{p} \overline{A_{c p}} / A_{t}$

where $\overline{A_{c p}}=\pi<R_{p}^{2}>$ is the average covered area of PIONPs. Then the nanoparticle stabilizing efficiency for submicron droplets is

$E_{p}=A_{t} / N_{p} \overline{A_{c p}}$

\section{Quantification of PIONP surface coverage on the whole interface of macroemulsions}

Three were three different emulsion droplets of submicron droplets, small droplets, and large droplets in the macroemulsion system. As the added oil volume $\left(V_{o p}\right)$ and the number of submicron droplets $\left(N_{s m d}\right)$ are known. Thus the whole oil volume is

$V_{o}=V_{\text {osmd }}+V_{a}=V_{\text {osmd }}+V_{\text {osd }}+V_{\text {old }}$

Where $V_{\text {osmd }}$ is the oil volume of submicron droplets added into the macroemulsion system, $V_{a}$ is the oil volume added with water to make macroemulsions, $V_{o s d}$ is the fraction of oil volume forming small droplets, $V_{\text {old }}$ is the oil volume fraction of becoming large droplets. The average radius of small droplets $\left(R_{s d}\right)$ could be estimated by LSCM imaging of the interface between large droplets (Fig. 3g) and the average radius of large droplets $\left(R_{l d}\right)$ could be acquired by calculating the Sauter diameter of droplets prepared by different concentration of submicron droplets (Fig. 4cg, Extended Data Fig. 13). Then the average interfacial area of submicron droplet is 
$\overline{A_{s m d}}=4 \pi<R_{s m d}^{2}>$

Then the average interfacial area of macroemulsion small droplets is

$\overline{A_{s d}}=4 \pi<R_{s d}^{2}>$

The average interfacial area of large droplets is

$\overline{A_{l d}}=4 \pi<R_{l d}^{2}>$

Because there is nearly the same surface small droplet coverage $\left(f_{s d}\right)$ between macroemulsion large droplets prepared by submicron droplets of $0.04 \mathrm{w} / \mathrm{v} \%$ and $0.1 \mathrm{wt} \%$ PIONPs ((Fig. 3h, j, Fig. 4h), we assumed that all the macroemulsion large droplets prepared by submicron droplets with low (0.02-0.15 wt $\%)$ concentration of PIONPs have the same $f_{s d}$ of $21 \%$. Then the number ratio $\left(N_{s d} / N_{l d}\right)$ is

$\frac{N_{s d}}{N_{l d}}=f_{s d} \overline{A_{l d}} / \overline{A_{c s d}}$

The ratio of $V_{\text {osd }} / V_{\text {old }}$ is

$\frac{V_{\text {osd }}}{V_{\text {old }}}=N_{s d} \overline{V_{s d}} / N_{l d} \overline{V_{l d}}$

The oil volume of small droplets is

$V_{\text {osd }}=V_{a} /\left(\frac{V_{\text {old }}}{V_{\text {osd }}}+1\right)$

The oil volume of large droplets is

$V_{\text {old }}=V_{a}-V_{\text {osd }}$ 
The total number of small droplets is

$N_{s d}=V_{o s d} / \overline{V_{s d}}$

The total number of large droplets is

$N_{l d}=V_{\text {old }} / \overline{V_{l d}}$

The total number of submicron droplets is

$N_{\text {smd }}=V_{\text {osmd }} / \overline{V_{\text {smd }}}$

The total interfacial area of small droplets is

$A_{t s d}=N_{s d} \overline{A_{s d}}$

The total interfacial area of large droplets is

$A_{\text {tld }}=N_{l d} \overline{A_{l d}}$

The total interfacial area of submicron droplets is

$A_{t s m d}=N_{s m d} \overline{A_{s m d}}$

Where $N_{s m d}$ is the number of submicron droplets added for preparing macroemulsions. Then the fraction of small droplet surface covered with nanoparticles is

$f_{s s d}=N_{p} \overline{A_{c p}} / A_{t s d}$

The fraction of macroemulsion large droplet surface covered with nanoparticles is 
$f_{s l d}=N_{p} \overline{A_{c p}} / A_{t l d}$

The total interfacial area of macroemulsion system is

$A_{t m}=N_{s m d} \overline{A_{s m d}}+N_{s d} \overline{A_{s d}}+N_{l d} \overline{A_{l d}}$

Then the fraction of macroemulsion droplet surfaces covered with nanoparticles is

$f_{\text {sm }}=N_{p} \overline{A_{c}} / A_{t m}$

The nanoparticle efficiency in the whole macroemulsion system is

$E_{p m}=A_{t m} / N_{p} \overline{A_{c}}$

\section{Quantification of submicron droplet surface coverage on the whole interface of macroemulsion}

ICP-OES measurements of aqueous phase of macroemulsion proved that all the PNDs jumped to oil-brine interface of small droplets and large droplets, because there were no residual PIONPs in the aqueous phase after preparation of macroemulsion with particle loadings (0.02-0.15 $\mathrm{wt} \%$ ). It was assumed that the submicron droplets like nanoparticles to form monolayers with hexagonal close-packed pattern. Then the average covered area of submicron droplets is

$\overline{A_{c s m d}}=\pi<R_{s m d}^{2}>$

The fraction of small droplet surface covered with submicron droplets is

$f_{s s d}=N_{s m d} \overline{A_{c s m d}} / A_{t s d}$

The fraction of large droplet surface covered with submicron droplet is

$f_{\text {sld }}=N_{\text {smd }} \overline{A_{\text {csmd }}} / A_{\text {tld }}$ 
The total interfacial area of macroemulsion system is

$A_{t m}=N_{s d} \overline{A_{s d}}+N_{l d} \overline{A_{l d}}$

Then the fraction of macroemulsion droplet surfaces covered with submicron droplets is

$f_{\text {sm }}=N_{\text {smd }} \overline{A_{\text {csmd }}} / A_{t m}$

The submicron droplet stabilizing efficiency in the whole macroemulsion system is

$E_{p m}=A_{t m} / N_{s m d} \overline{A_{c s m d}}$

\section{Reference:}

28. Pilapil, B. K., Jahandideh, H., Bryant, S. L. \& Trifkovic, M. Stabilization of oil-in-water emulsions with noninterfacially adsorbed particles. Langmuir 32, 7109-7116 (2016).

\section{Acknowledgments}

The authors thank Dr. Christopher DeBuhr and Brian Baillie for their help in obtaining SEM images and ICP-MS measurements at the University of Calgary, and Xu Tang from the Institute of Geology and Geophysics, CAS for helping capture the TEM images. We are also grateful to Drs. Paula Berton, Ali Telmadarreie, and Simon Trudel for their beneficial discussions. This work was supported by the Strategic Priority Research Program of Chinese Academy of Sciences (XDB41010403), National Natural Science Foundation of China grants $(41774076,41621004)$, Key Program of Chinese Academy of Sciences (QYZDJ-SSWDQC024), the Key Research Program of the Institute of Geology \& Geophysics, CAS (grant no. IGGCAS-201903), and the scholarship support from China Scholarship Council (grant no. 201704910005). E. A., A. M., B. K. P., A. K. M. T. and S. L. B. are grateful for the financial support from the Canadian Excellence Research Chair in Materials Engineering for Unconventional Reservoirs. 


\section{Author contributions}

C. C. conceived the idea for the study. C. C., E. A., A. M., A. K., and S. L. B. made contributions to the design of the experiments. J. Z., C. C. and E. A. conducted rheological study. A. M., C. C., B. K. P. and M. T. carried out LSCM imaging. J. W. and C. C. made STXM imaging. J. Y. did TEM imaging. C. C. and P. G. performed AFM imaging. S. L. B., C. C., J. Z., Y. Z. and F. F. performed quantitative analysis. C. C., S. L. B. and Y. P. interpreted the data and wrote the manuscript.

Competing interests: Authors declare no competing interests.

\section{Additional information}

Supplementary information The online version contains supplementary material available at ... Correspondence and requests for materials should be addressed to C. C. and S. L. B. 

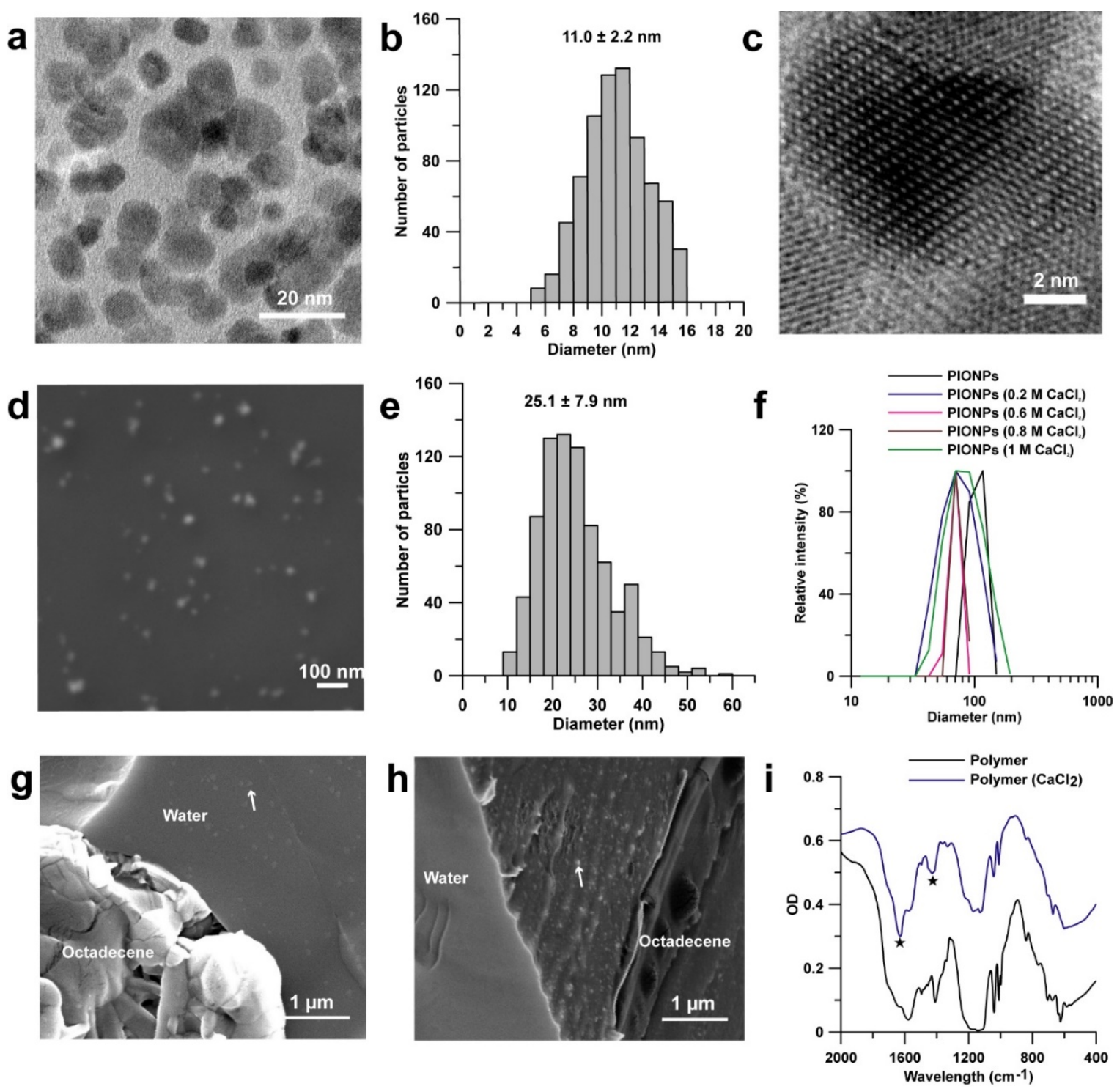

Extended Data Fig. 1| Structural characterization of PIONPs. a, TEM image of iron oxide cores. b, Size distribution histogram of cores. c, High-resolution TEM image of a core demonstrating crystalline $\mathrm{Fe}_{3} \mathrm{O}_{4}$ structure. d, SEM image of PIONPs. e, Size distribution histogram of PIONPs. f, Negligible change of the hydrodynamic size of PIONPs $(0.1 \mathrm{wt} \%)$ in water and high (0.2-1 M) ionic strength of $\mathrm{CaCl}_{2}$ showing the stability of PIONPs. $\mathbf{g}, \mathbf{h}$, Cryo-SEM images of PIONPs (white arrow) before (g) and after (h) binding calcium ions at the 1-octadecene-water interface. i, FTIR spectroscopy analysis of carboxylate and sulfonic groups of polymers PSS-coMA before and after incubation with $0.4 \mathrm{M} \mathrm{CaCl}_{2}$. Two peak shifts (black stars) from 1576 to $1630 \mathrm{~cm}^{-1}$ and 1409 to $1427 \mathrm{~cm}^{-1}$ when $\mathrm{Ca}^{2+}$ is present indicates that the polymer on the surface of nanoparticles can bind calcium ions through the carboxylate group. 

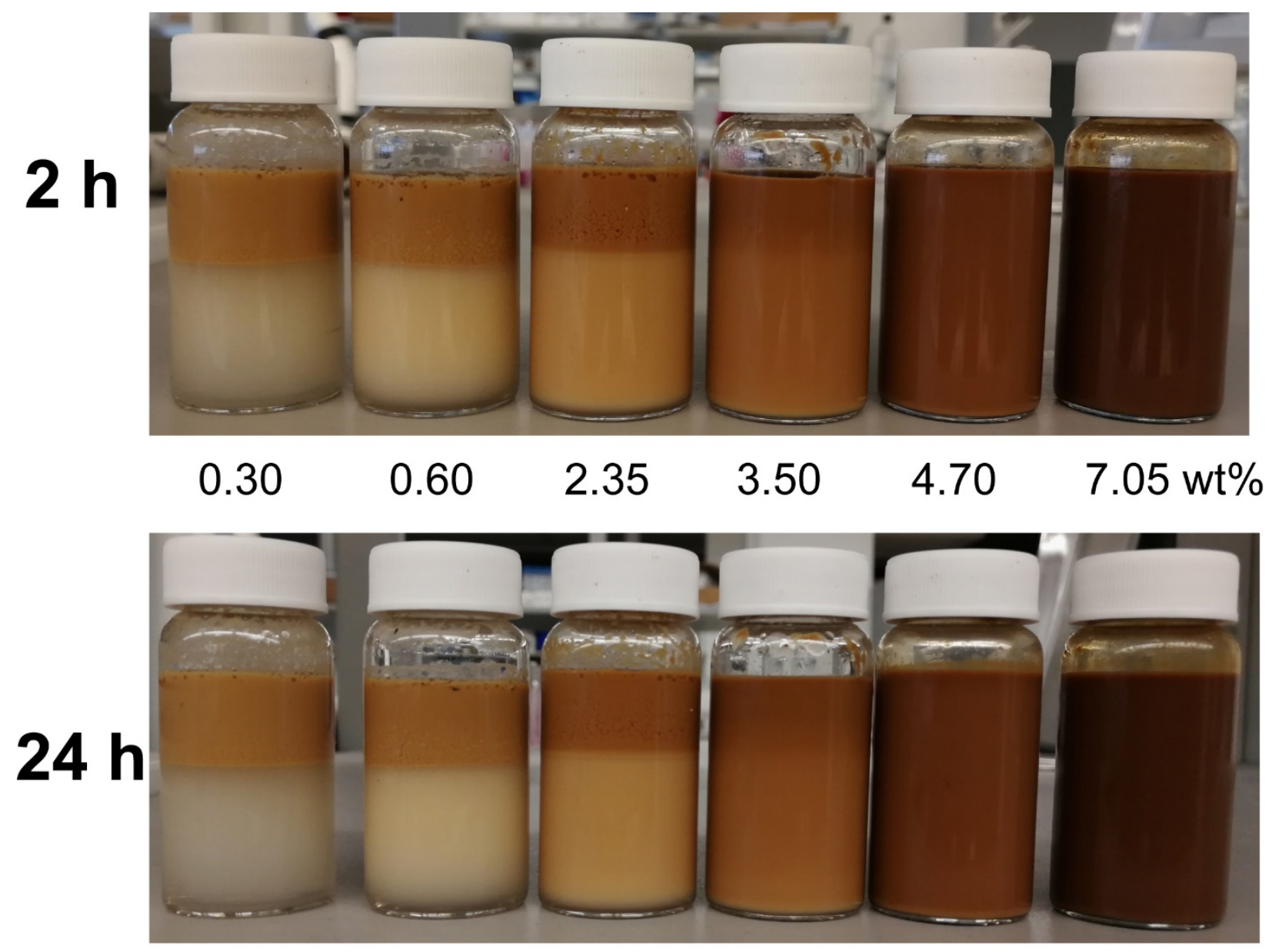

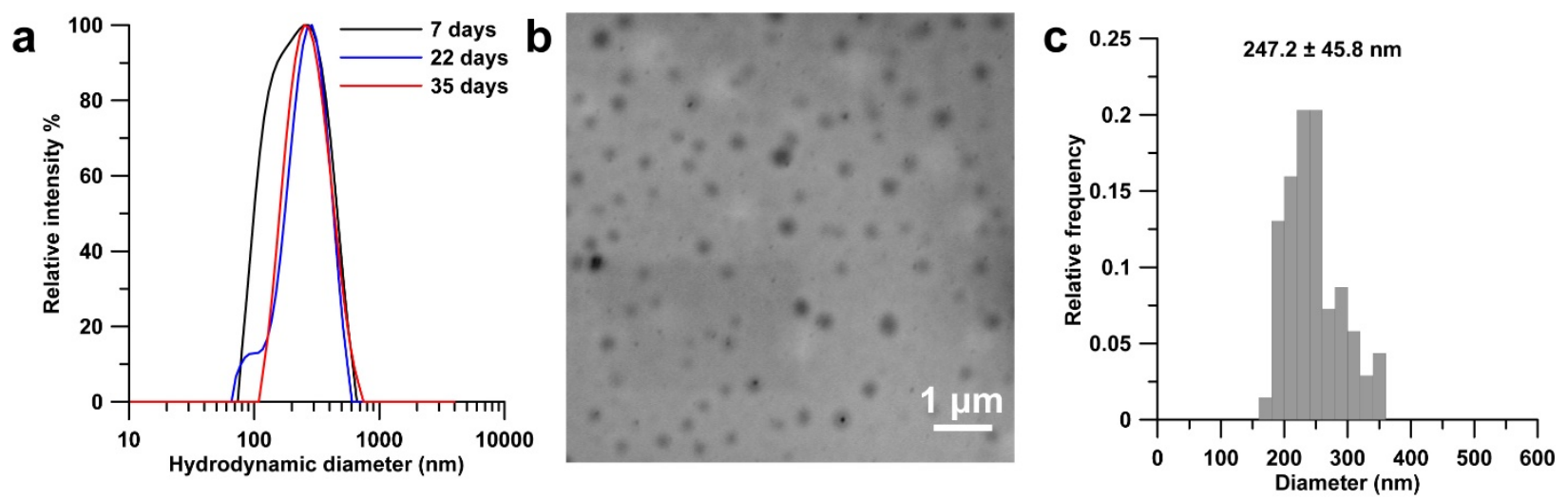

Extended Data Fig. 3| Size distribution of submicron droplets stabilized by PIONPs of 5.1 wt\% in $0.4 \mathrm{M} \mathrm{CaCl}_{2}$. a, Hydrodynamic size distribution of submicron droplets during settling for 7, 22 and 35 d. b, Liquid cell SEM image of submicron droplets. The image was acquired using dark-field scanning transmission electron microscope (STEM) mode. c, Size distribution histogram of submicron droplets from the liquid cell SEM image. 

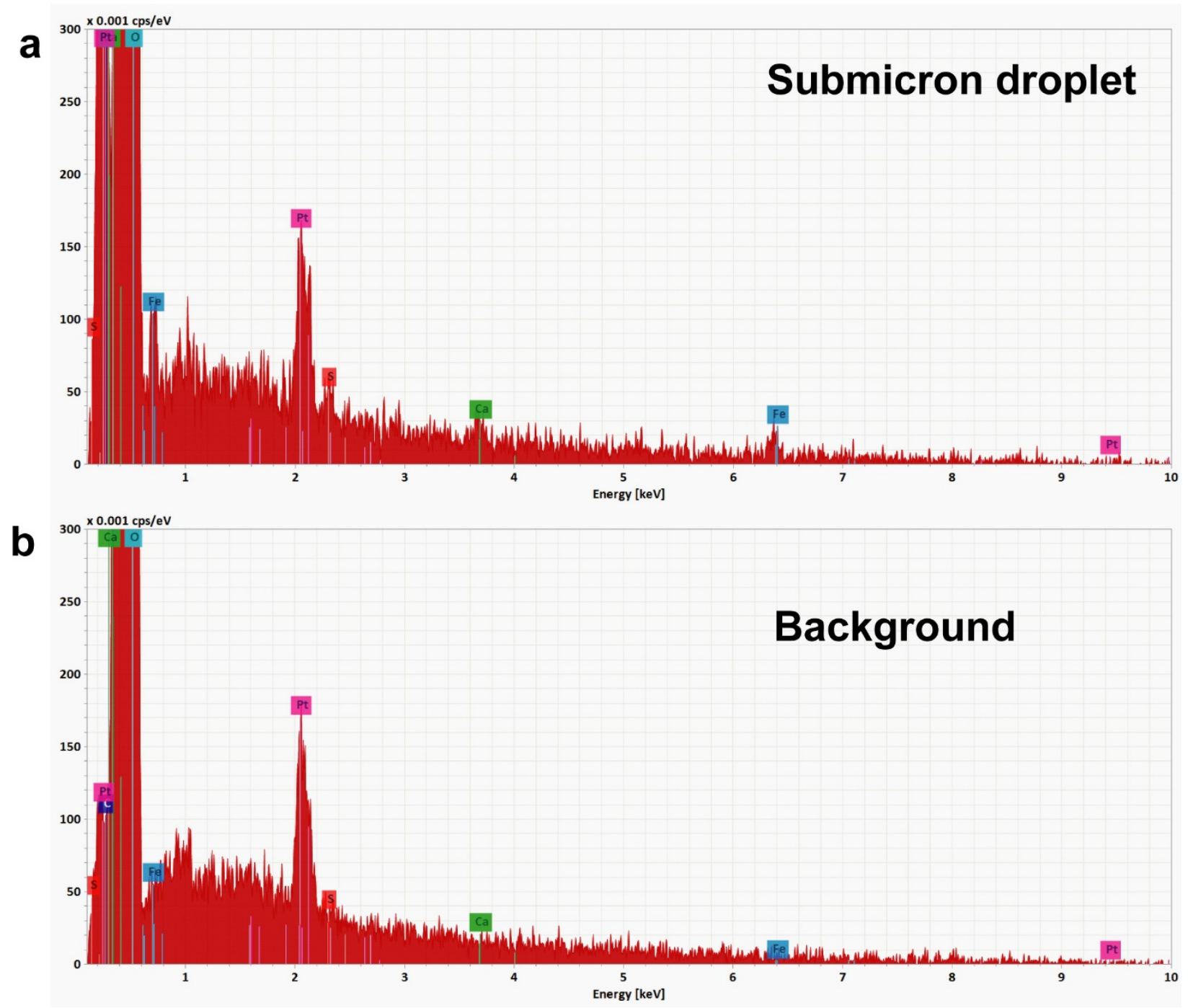

Extended Data Fig. 4| X-ray spectroscopy spectra of a submicron droplet (a) and water background (b). 

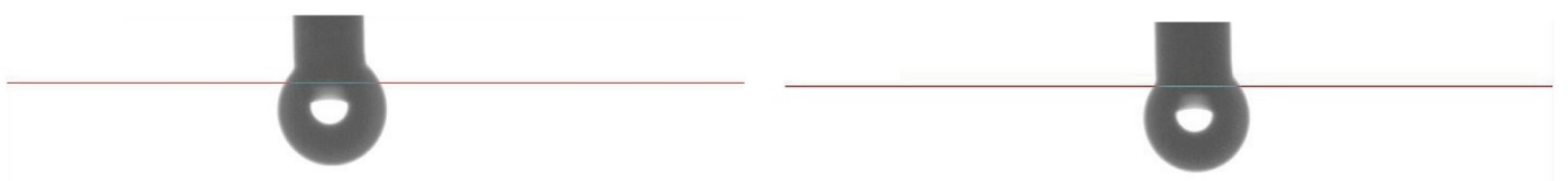

$4.4^{\circ}$

$15.1^{\circ}$

\section{Glass}
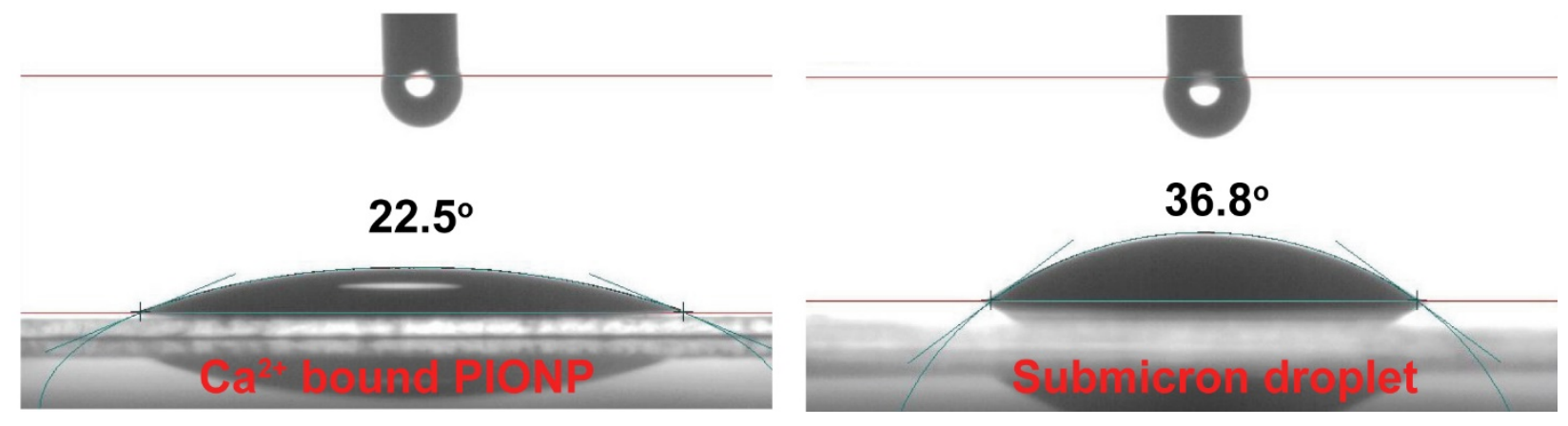

Extended Data Fig. 5| The contact angle of water on uncoated and coated cover slips with PIONPs, $\mathrm{Ca}^{2+}$ bound PIONPs and submicron droplets at ambient condition. The submicron droplets shows more hydrophobicity than PIONPs and $\mathrm{Ca}^{2+}$ bound PIONPs. 

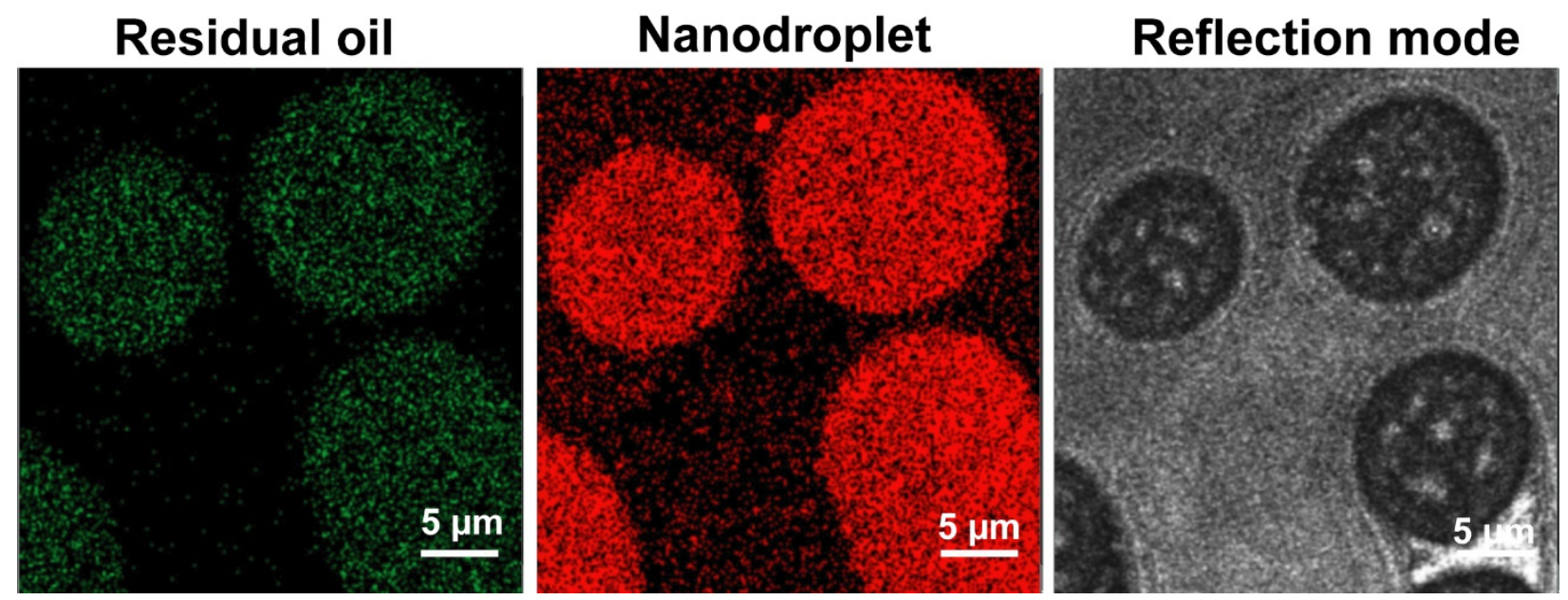

Extended Data Fig. 6| LSCM imaging of the residual oil (green) site when nanodroplets (red) flow through a 2-D microfluidic model. The reflection mode image shows that bigger micronsized droplets were created and subsequently held at the oil-brine interface. 

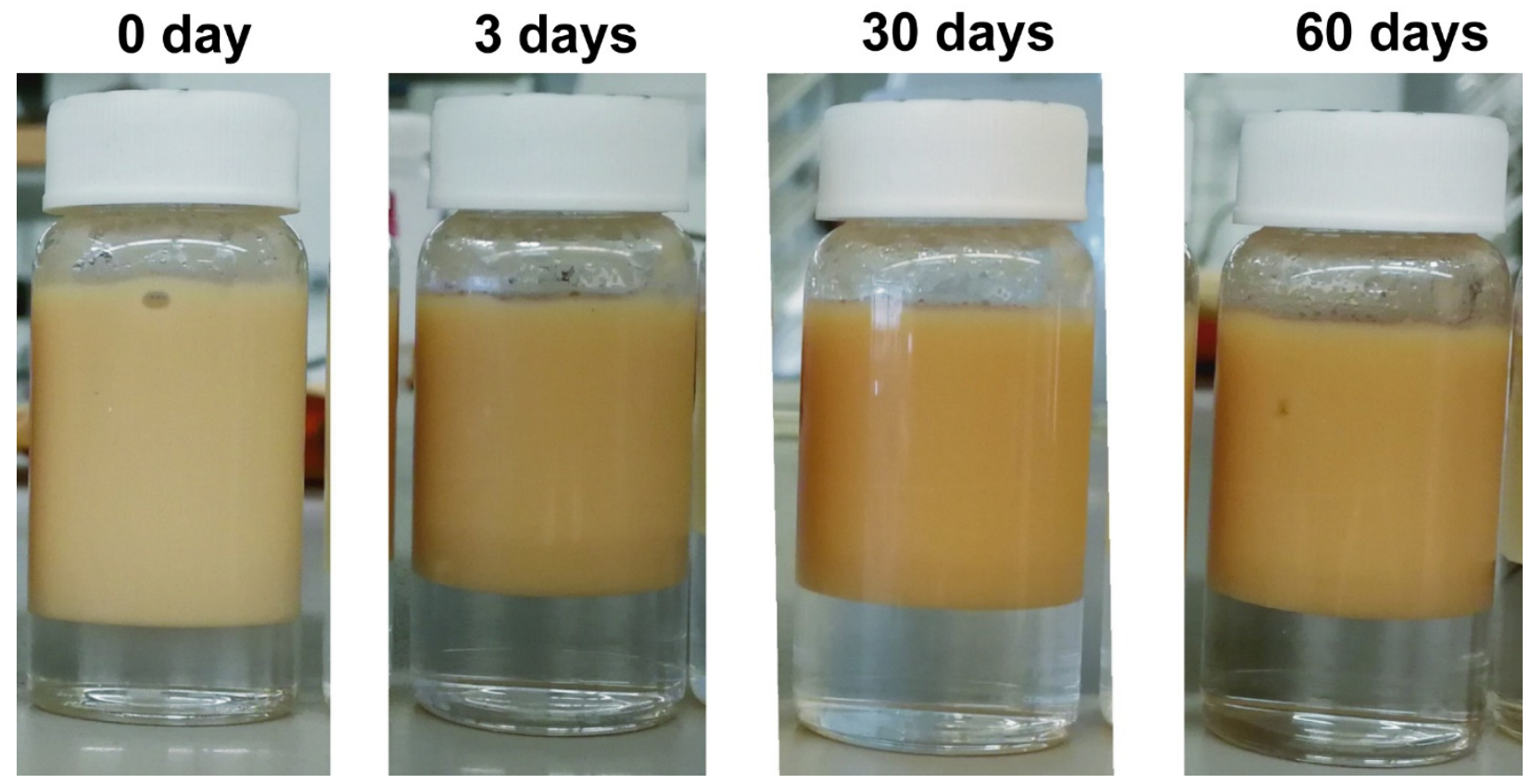

Extended Data Fig. 7| Digital photographs of 1-octadecene-in-brine macroemulsions prepared by submicron droplets with $0.1 \mathrm{wt} \%$ PIONPs. The photographs were acquired at different days after the preparation. 


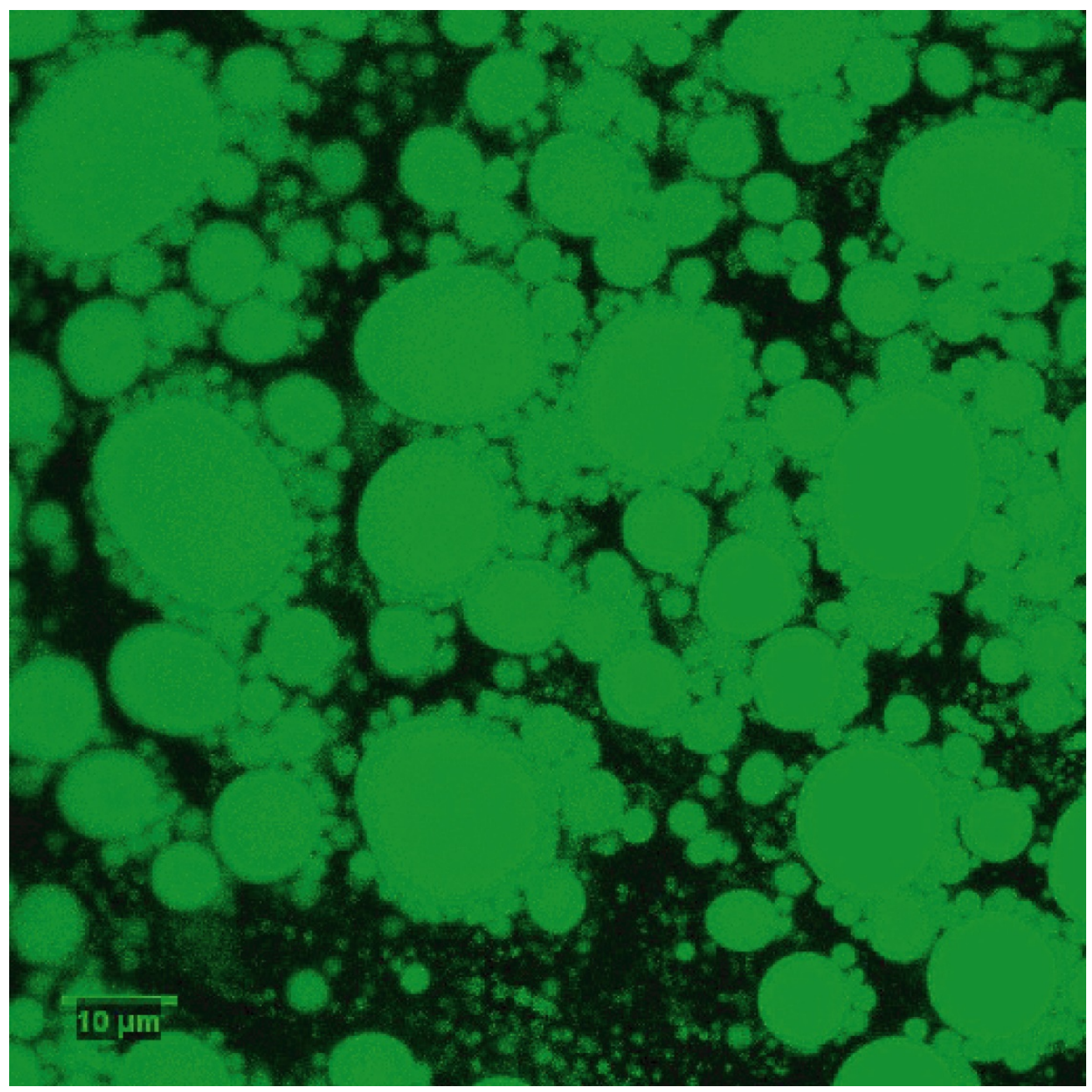

Extended Data Fig. 8| 2D LSCM image of 1-octadecene-in-brine macroemulsions prepared by submicron droplets (0.1 wt\% PIONPs). The oil (green) is labeled with perylene, whereas the water phase (black) is unlabeled. 

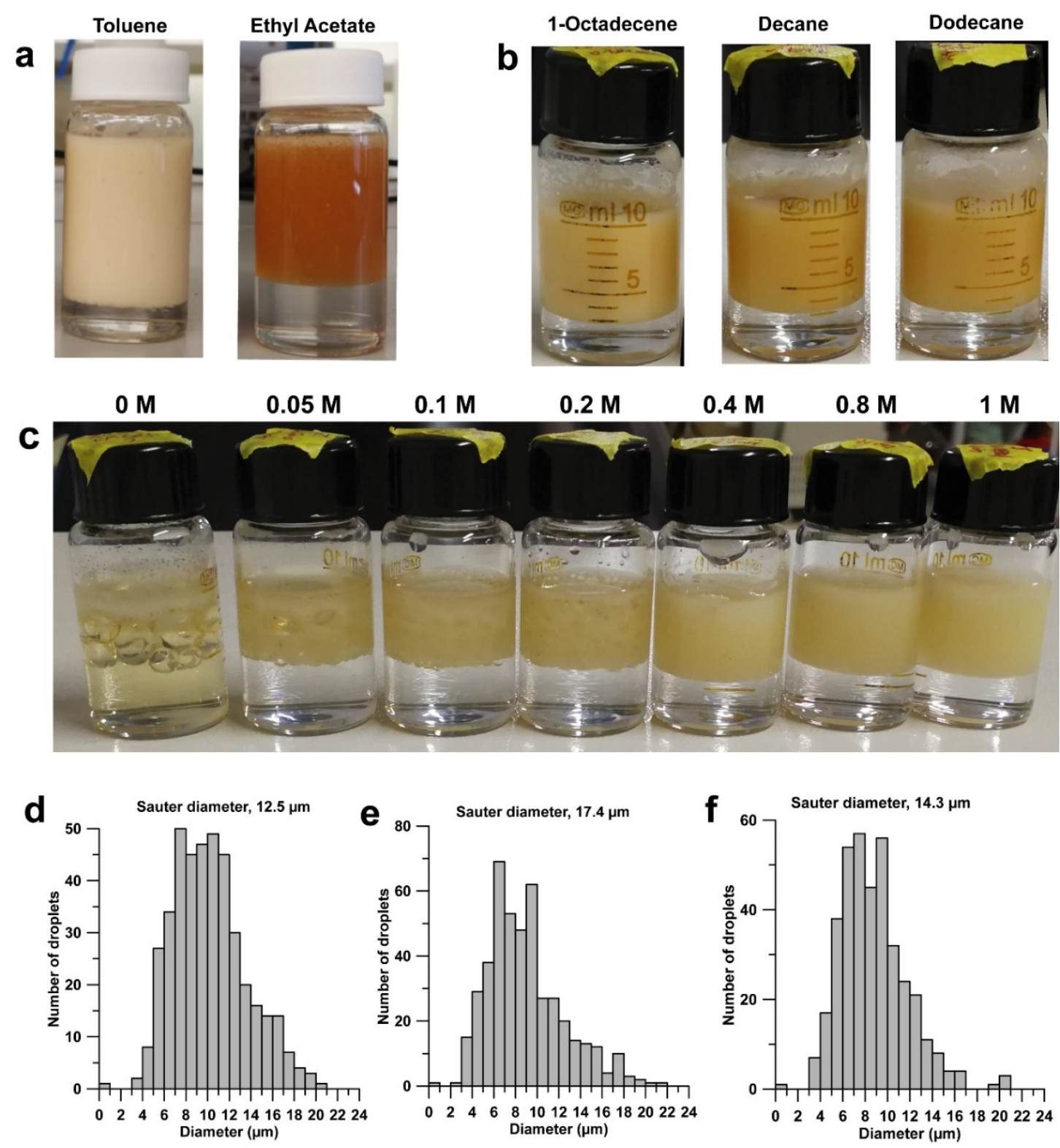

Extended Data Fig. 9| Effect of oil polarity in the hierarchical stabilization mode. a, Nonpolar oil of toluene-in-brine and more polar oil of ethyl acetate-in-brine macroemulsions $(10 \mathrm{~mL}$ of each phase) formed by submicron droplets of $0.1 \mathrm{wt} \%$ PIONPs at $0.4 \mathrm{M} \mathrm{CaCl}_{2}$. The images were taken after aging 2 d. b, Nonpolar oil of 1-octadecene, decane and dodecane macroemulsions ( $5 \mathrm{~mL}$ of each phase) formed by submicron droplets of $0.1 \mathrm{wt} \%$ PIONPs at $0.4 \mathrm{M} \mathrm{CaCl}_{2}$. c, 1-Octadecene macroemulsions with very low particle loadings of $0.02 \mathrm{wt} \%$ in different $(0-1 \mathrm{M})$ concentration of $\mathrm{CaCl}_{2}$. The photographs (b and $\mathbf{c}$ ) were acquired after aging $11 \mathrm{~d}$. d-f, Size distribution histograms of 1-octadecene (d), decane (e) and dodecane (f) macroemulsions observed by microscope after aging $11 \mathrm{~d}$. 

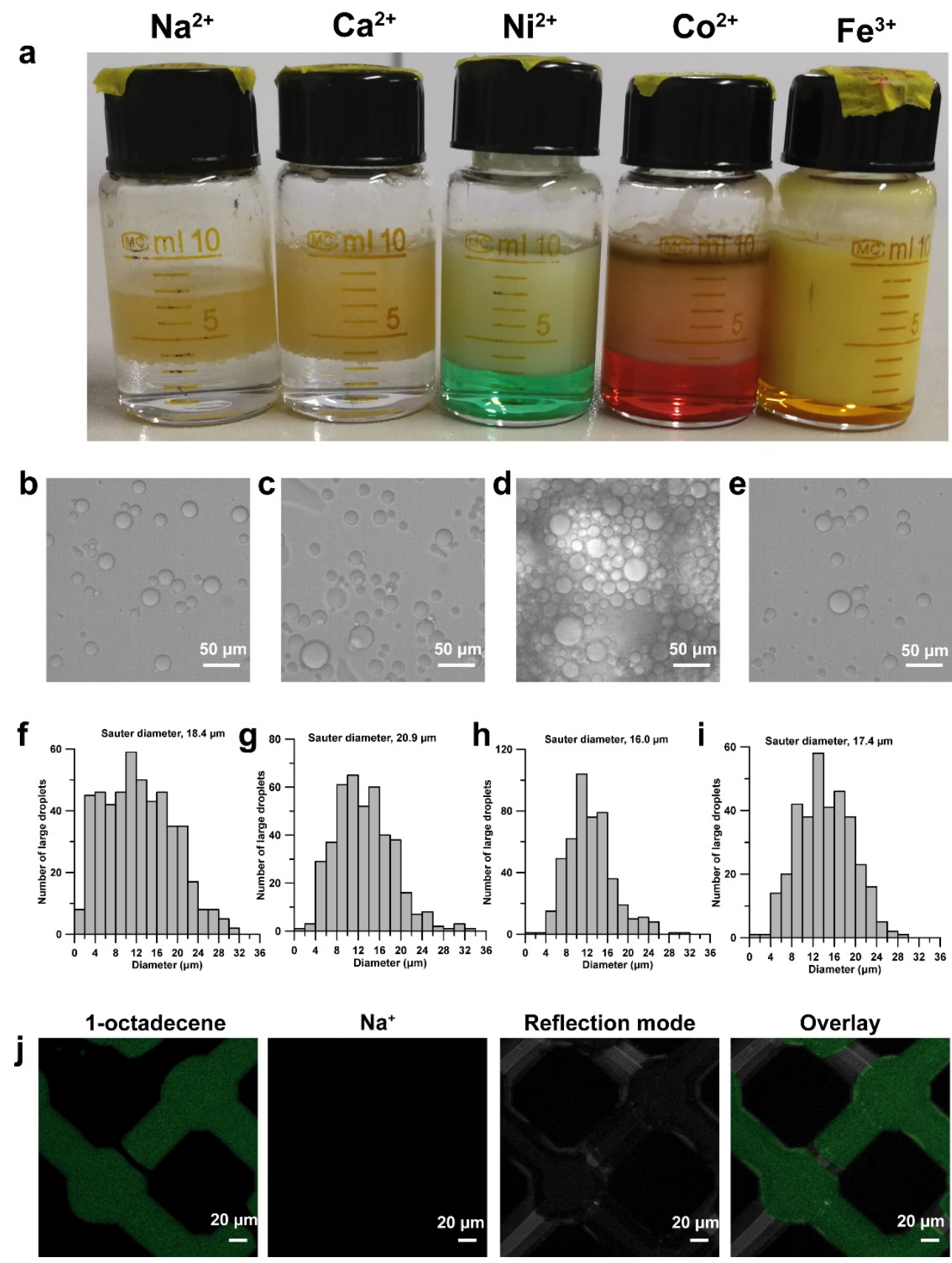

Extended Data Fig. 10| Effect of metal ions in the hierarchical stabilization mode. a, 1Octadecene-in-brine macroemulsions formed by submicron droplets of $0.04 \mathrm{wt} \%$ PIONPs at $0.4 \mathrm{M}$ $\mathrm{NaCl}, \mathrm{CaCl}_{2}, \mathrm{NiCl}_{2}, \mathrm{CoCl}_{2}$ and $\mathrm{FeCl}_{3}$. The photographs were taken after aging $11 \mathrm{~d}$. b-e, Optical microscope images of 1-octadecene macroemulsions prepared by submicron droplets in presence of $0.4 \mathrm{M} \mathrm{CaCl}_{2}(\mathbf{b}), \mathrm{NiCl}_{2}(\mathbf{c}), \mathrm{CoCl}_{2}$ (d) and $\mathrm{FeCl}_{3}(\mathbf{e})$. f-i, Size distribution histograms of 1octadecene macroemulsion in $0.4 \mathrm{M} \mathrm{CaCl}_{2}(\mathbf{f}), \mathrm{NiCl}_{2}(\mathbf{g}), \mathrm{CoCl}_{2}(\mathbf{h})$ and $\mathrm{FeCl}_{3}$ (i). The microscope images (b-e) and size distribution histograms (f-i) were acquired after aging $2 \mathrm{~d}$. (j) LSCM images show that $0.2 \mathrm{M}$ sodium ions are not associated with the nonpolar oil of 1-octadecene. The oil is labeled green, and metal ions are detected as red fluorescence. 

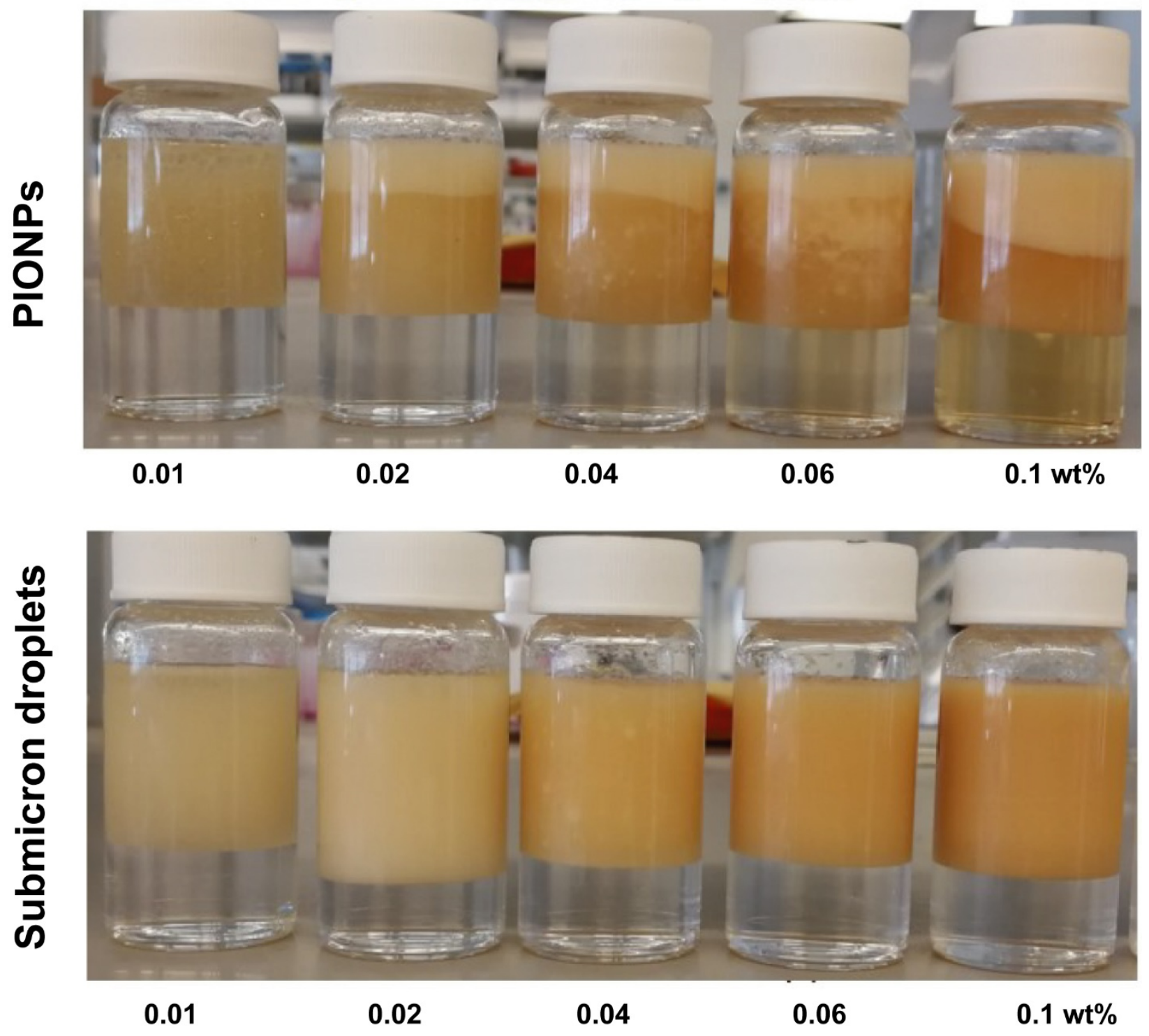

Extended Data Fig. 11| Digital photographs of 1-octadecene-in-brine macroemulsions prepared by PIONPs and submicron droplets with different concentrations (0.01-0.1 wt\%) of PIONPs in $0.4 \mathrm{M} \mathrm{CaCl}_{2}$. The photographs were acquired $38 \mathrm{~d}$ after the preparation. 

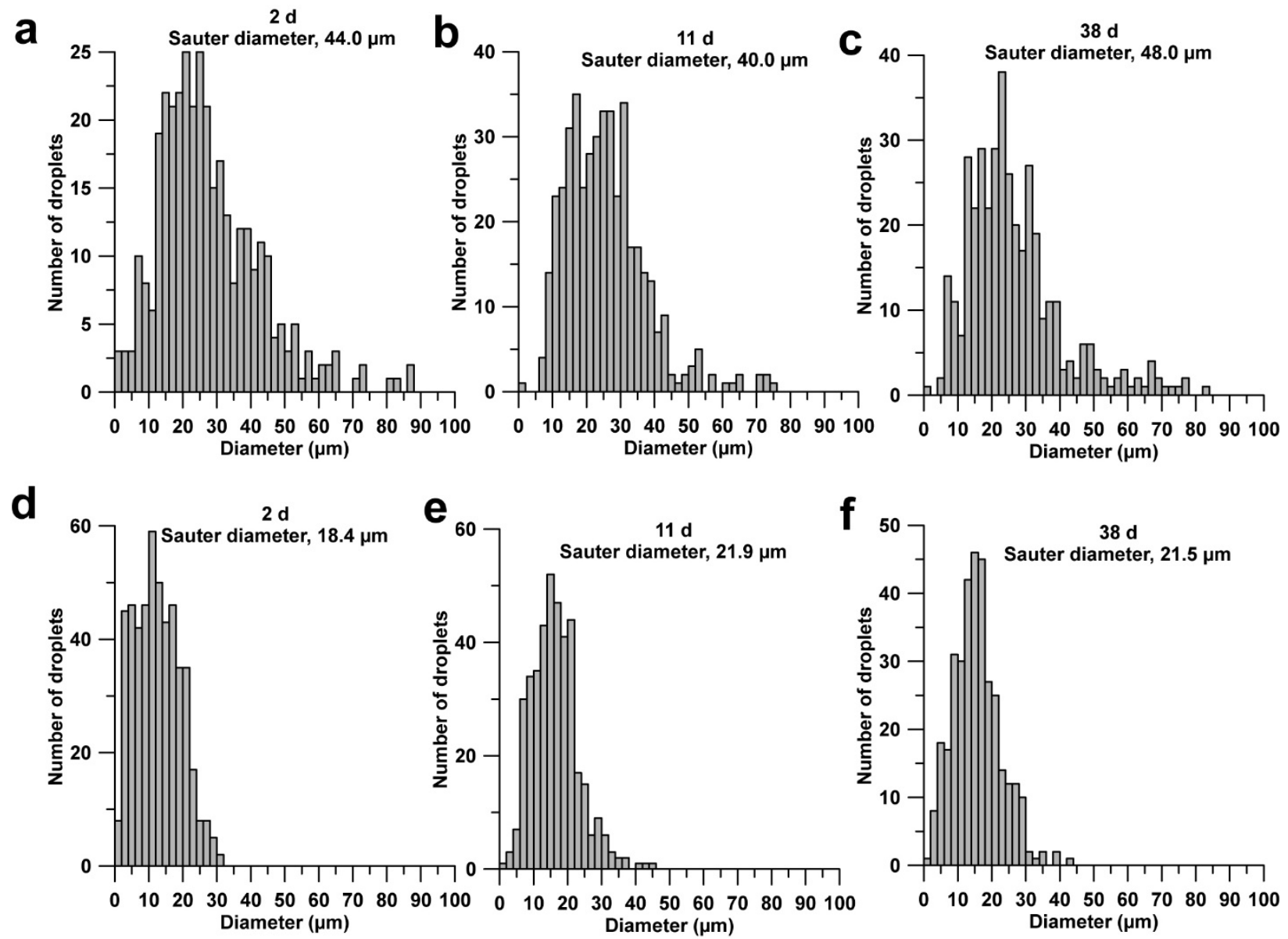

Extended Data Fig. 12 Size distribution histograms of 1-octadecene-in-brine macroemulsions with low particle loadings of $0.02 \mathrm{wt} \%$ (a-c) and $0.04 \mathrm{wt} \%$ (d-f) after aging $2 \mathrm{~d}, 11 \mathrm{~d}$, and $38 \mathrm{~d}$. 


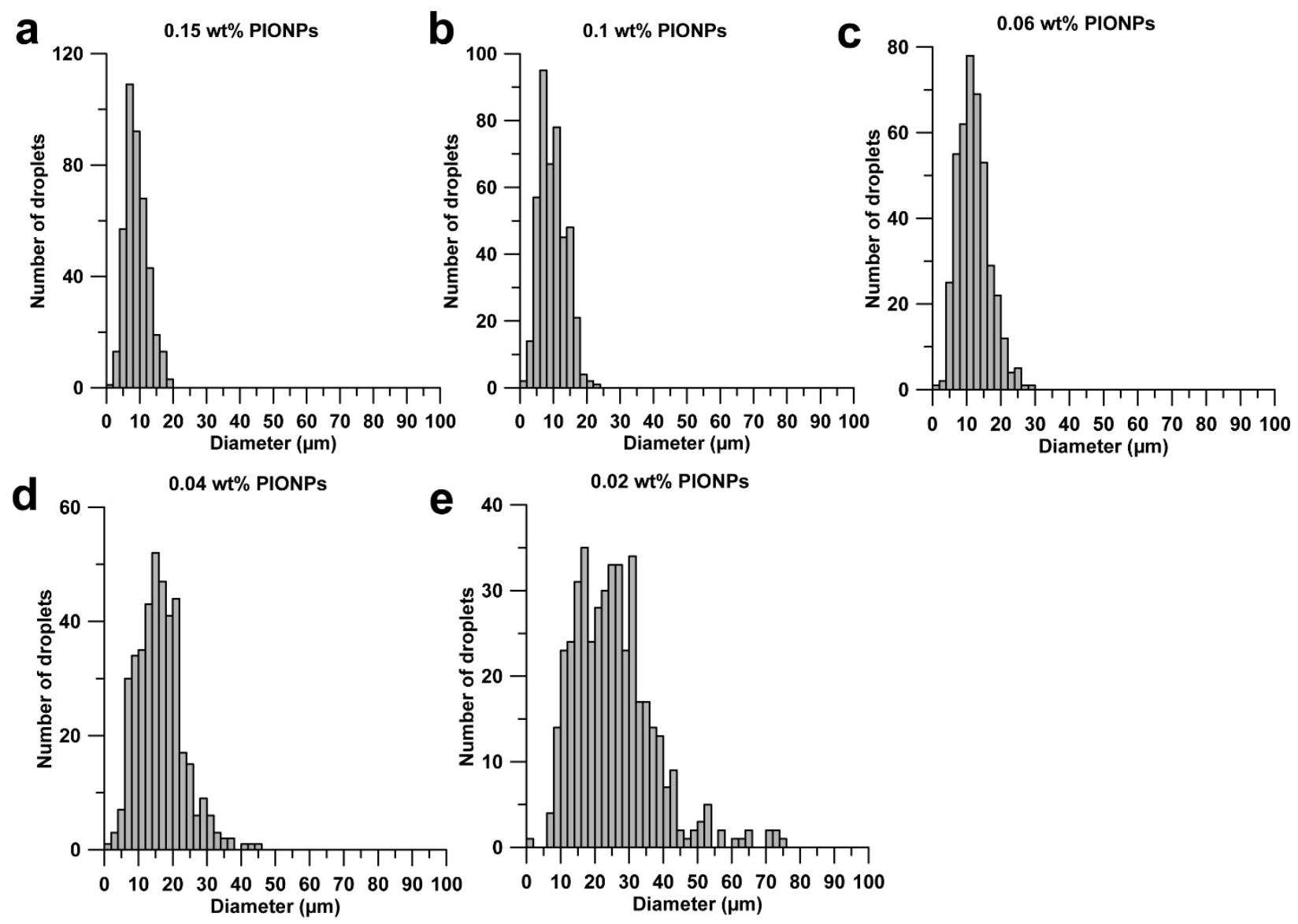

Extended Data Fig. 13| Size distribution histograms of 1-octadecene-in-brine macroemulsions prepared by submicron droplets at different concentration (0.02-0.15 wt\%) of PIONPs. All the macroemulsion droplet sizes were measured through microscope images after aging $11 \mathrm{~d}$. 

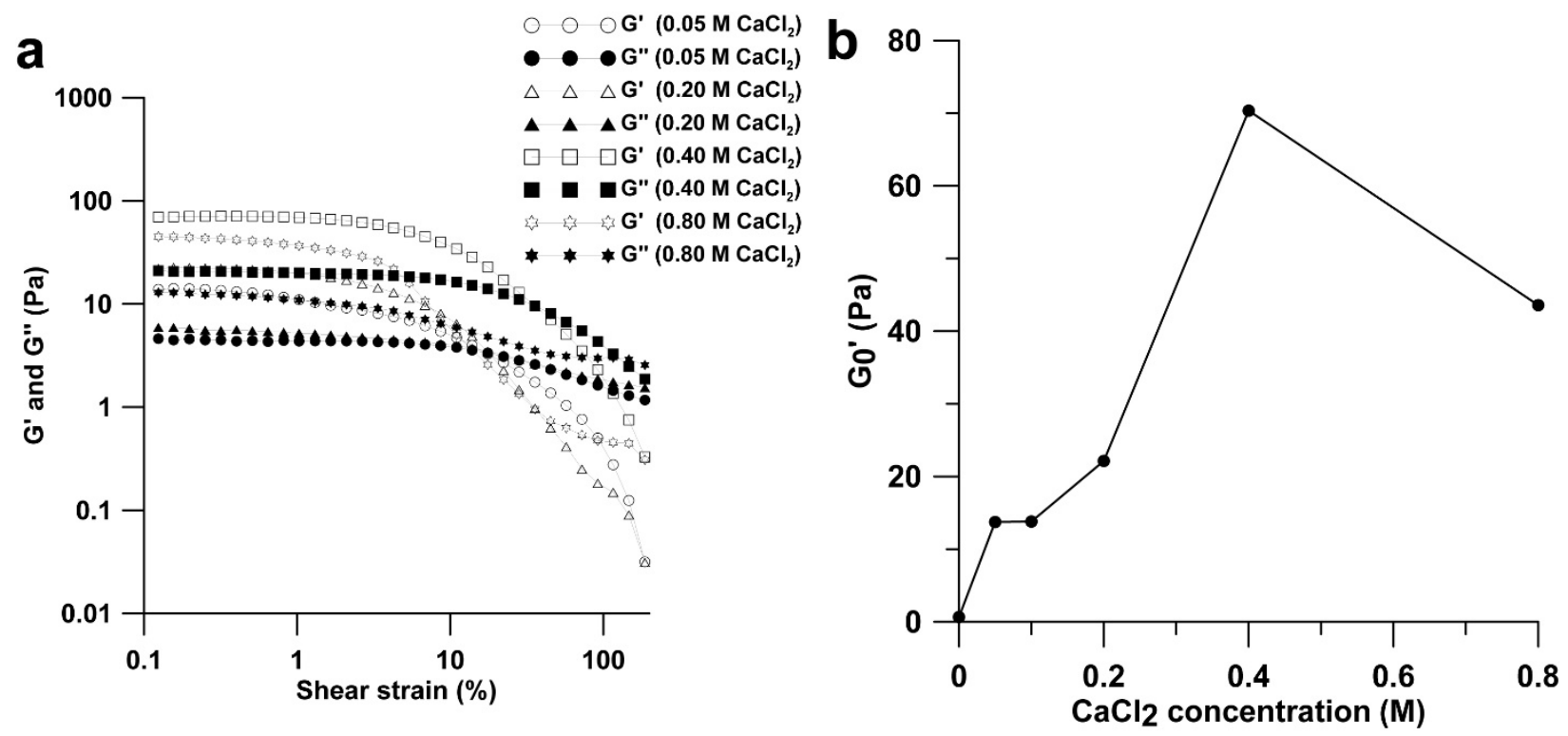

Extended Data Fig. 14| Comparison of elasticity for hierarchical emulsion prepared by submicron droplets in different concentration of $\mathbf{C a C l}_{2}$. a, Strain dependence of the elastic storage modulus (G', open symbols) and viscous loss modulus (G', filled symbols) of hierarchical emulsion (50\% 1-octadecene) with $0.1 \mathrm{wt} \%$ PIONP loading at different concentration of $\mathrm{CaCl}_{2} . \mathbf{b}$, The zero shear elastic storage modulus $\left(\mathrm{G}_{0}{ }^{\prime}\right)$ of emulsion (0.1 wt\% PIONPs) versus $\mathrm{CaCl}_{2}$ concentration. The maximum $\mathrm{G}_{0}$ ' and cross over frequency (indicating highest yield stress) of macroemulsion were achieved at $0.4 \mathrm{M} \mathrm{CaCl}_{2}$. All the macroemulsions were characterized after aging $11 \mathrm{~d}$. 

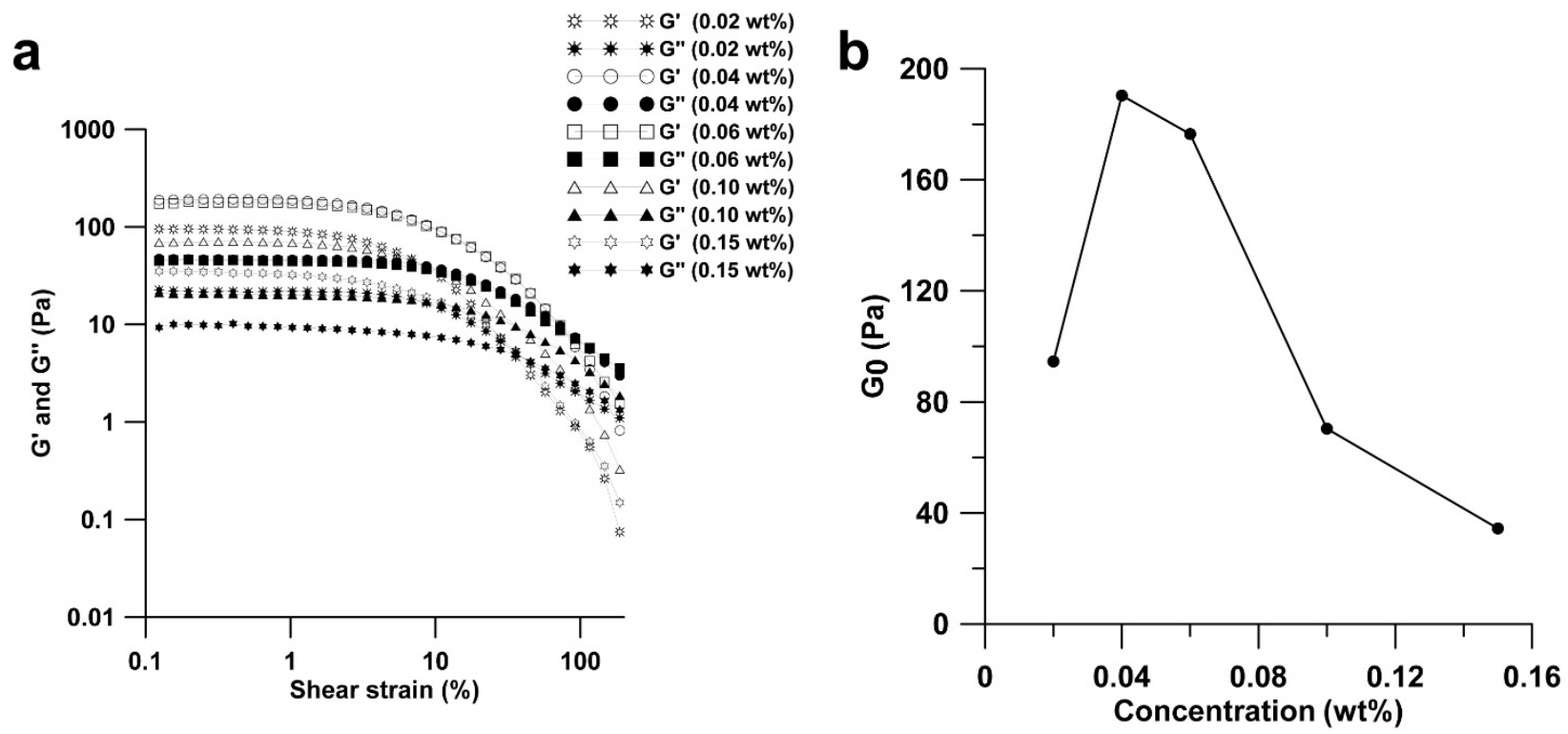

Extended Data Fig. 15| Comparison of elasticity for hierarchical emulsion prepared by submicron droplets with different concentration of PIONPs. a, Strain dependence of G' (open symbols) and G', (filled symbols) of hierarchical emulsion (50\% 1-octadecene) prepared by submicron droplets with different (0.02-0.15 wt \%) concentrations of PIONPs in $0.4 \mathrm{M} \mathrm{CaCl}_{2}$. b, G0' of hierarchical emulsion in $0.4 \mathrm{M} \mathrm{CaCl}_{2}$ versus PIONP concentration. The maximum $\mathrm{G}_{0}$ ' was achieved at PIONP loading of $0.04 \mathrm{wt} \%$. All the macroemulsions were characterized after aging $11 \mathrm{~d}$. 

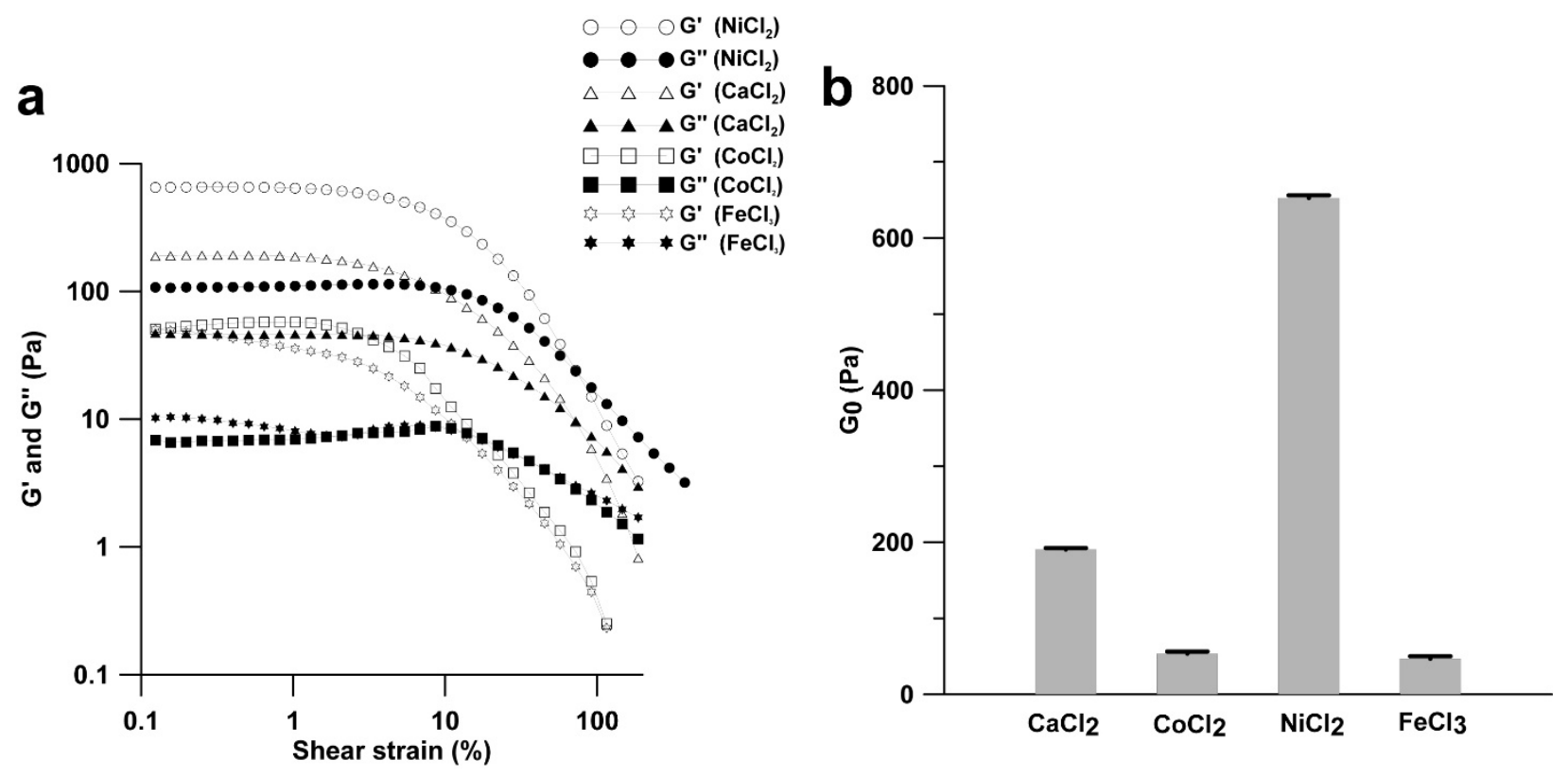

Extended Data Fig. 16| Comparison of elasticity for hierarchical emulsion prepared in presence of different metal ions. a, Strain dependence of G' (open symbols) and G', (filled symbols) of hierarchical emulsion (50\% 1-octadecene) prepared by submicron droplets of 0.04 wt \% PIONP at $0.4 \mathrm{M} \mathrm{CaCl}_{2}, \mathrm{CoCl}_{2}, \mathrm{NiCl}_{3}$, and $\mathrm{FeCl}_{3}$. b, Comparison of $\mathrm{G}_{0}$ ' of hierarchical emulsion at $0.4 \mathrm{M} \mathrm{CaCl}_{2}, \mathrm{CoCl}_{2}, \mathrm{NiCl}_{3}$, and $\mathrm{FeCl}_{3}(\mathrm{n}=5)$. The maximum $\mathrm{G}_{0}$ ' was achieved at PIONP loading of $0.04 \mathrm{wt} \%$ in $0.4 \mathrm{M} \mathrm{NiCl}_{2}$. All the macroemulsions were characterized after aging $11 \mathrm{~d}$. 


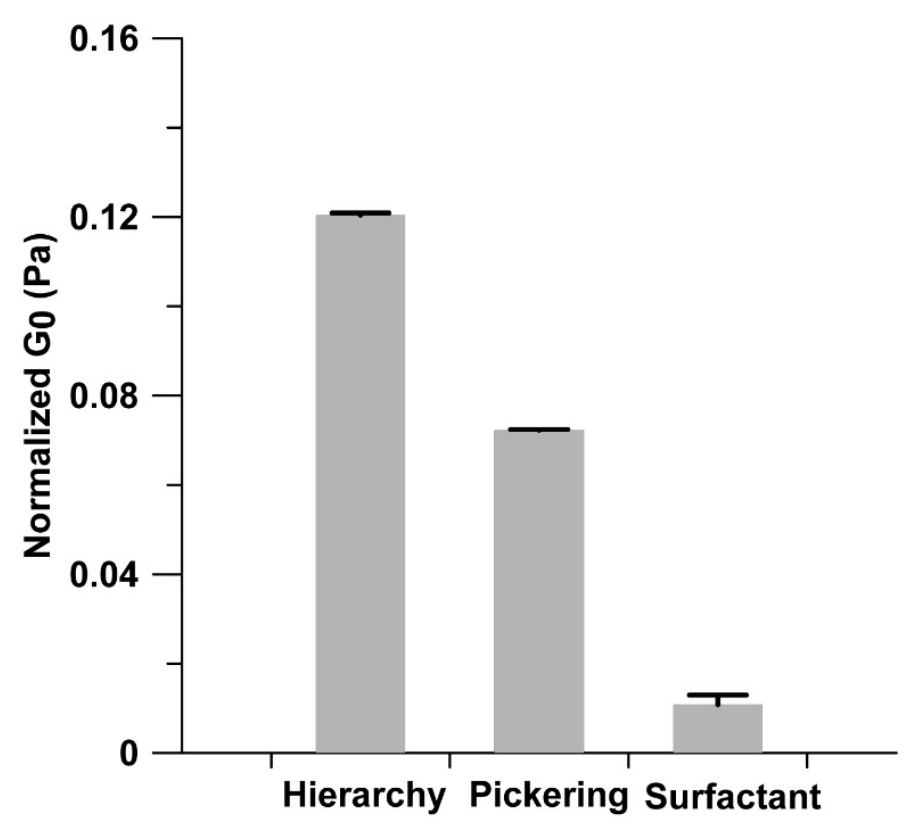

Extended Data Fig. 17| Comparison of elasticity for hierarchical oil-in-brine emulsion, Pickering oil-in-water emulsion and surfactant stabilized oil-in-water emulsion. The Pickering oil-in-water emulsion is stabilized by Hexamethyldisilazane (HDMS) modified $\mathrm{SiO}_{2}$ nanoparticles ( $\sim 20 \mathrm{~nm}, 1.5 \mathrm{wt} \%)$. The surfactant stabilized oil-in-water emulsions is prepared by $2 \mathrm{wt} \%$ Sodium dodecyl sulfate (SDS) with $50 \% 1$-octadecene. The $\mathrm{G}_{0}$ is normalized by Laplace pressure, the ratio of the oil-water interfacial tension to the Sauter diameter $(\mathrm{n}=3)$. All the macroemulsions were characterized after aging $11 \mathrm{~d}$. 

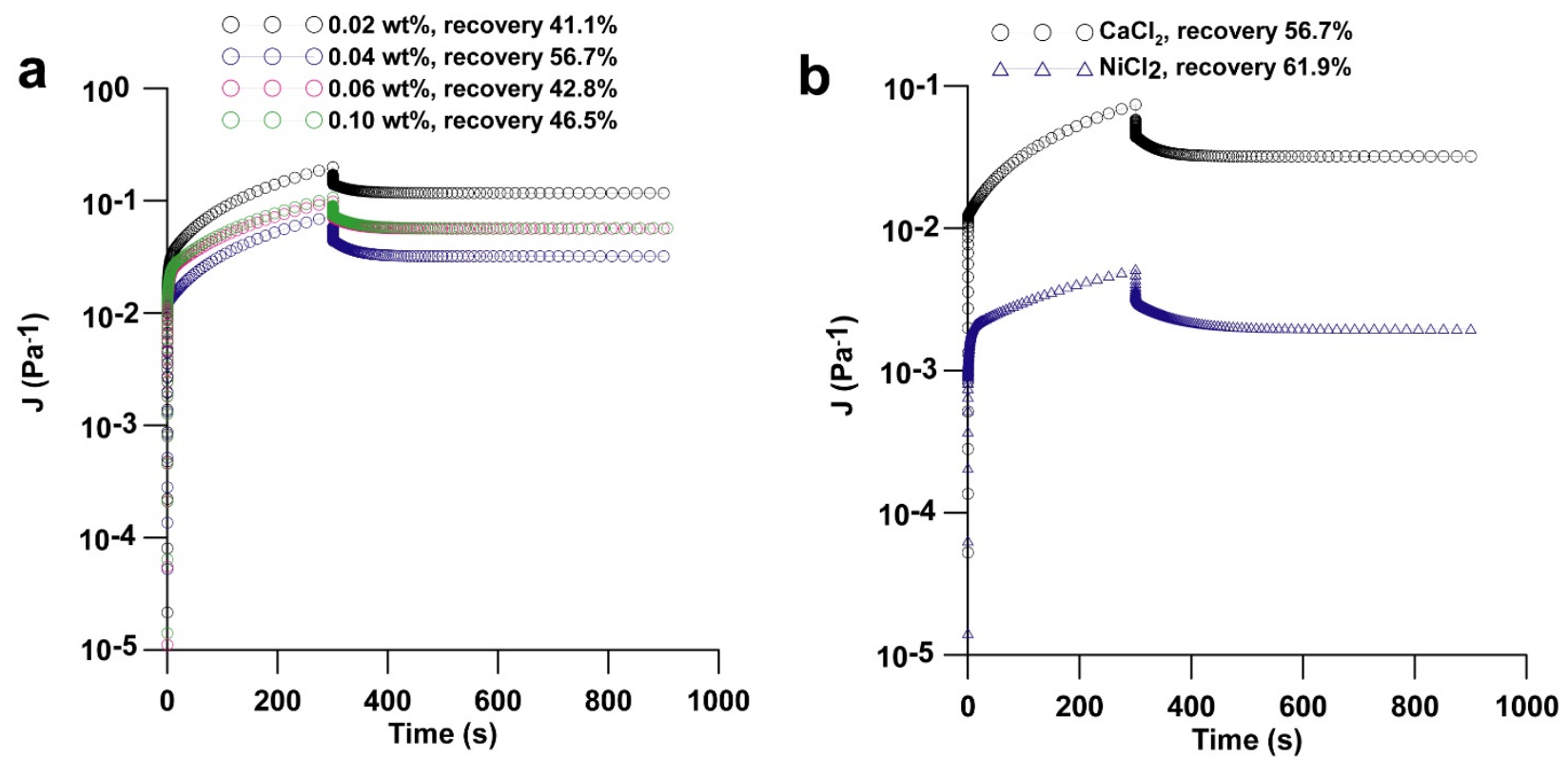

Extended Data Fig. 18| Comparison of deformability for hierarchical emulsion prepared with different particle loadings and metal ions. a, Compliance versus time in creep and recovery test for hierarchical emulsion prepared by submicron droplets with different $(0.02-0.10 \mathrm{wt} \%)$ PIONP loadings. b, Creep and recovery test for hierarchical emulsion prepared by submicron droplets $(0.04 \mathrm{wt} \% \mathrm{PIONP})$ in $0.4 \mathrm{M} \mathrm{CaCl}_{2}$ and $\mathrm{NiCl}_{2}$. The minimum compliance and maximum recovery were achieved at PIONP loading of $0.04 \mathrm{wt} \%$ in $0.4 \mathrm{M} \mathrm{NiCl}_{2}$. All the macroemulsions were characterized after aging $11 \mathrm{~d}$. 
Extended Data Table 1| Zeta potential of PIONPs and submicron droplets

\begin{tabular}{ccccc}
\hline & PIONPs & PIONPs $\left(0.4 \mathrm{M} \mathrm{CaCl}_{2}\right)$ & Submicron droplets & 1-octadecene \\
\hline Zeta potential $(\mathrm{mV})$ & -71.0 & -25.7 & -23.2 & 0 \\
\hline
\end{tabular}


Extended Data Table 2| Quantification of the PIONP surface coverage on submicron droplets

\begin{tabular}{|c|c|c|c|c|c|c|c|c|c|c|c|}
\hline $\begin{array}{l}\text { Concentration } \\
\text { (wt } \% \text { in } \\
\text { aqueous phase) }\end{array}$ & $\begin{array}{c}\text { PIONP } \\
\text { Size (nm) }\end{array}$ & $\begin{array}{l}\text { PIONP } \\
\text { mass } \\
(\mathrm{Kg})\end{array}$ & $\begin{array}{l}\text { Density } \\
\left(\mathrm{Kg} / \mathrm{m}^{3}\right)\end{array}$ & $\begin{array}{l}\text { PIONP } \\
\text { covered } \\
\text { area }\left(\mathrm{m}^{2}\right)\end{array}$ & $\begin{array}{c}\text { Droplet } \\
\text { size } \\
(\mu \mathrm{m})\end{array}$ & $\begin{array}{c}\text { Oil } \\
(\mathrm{mL})\end{array}$ & $\begin{array}{l}\text { Brine } \\
(\mathrm{mL})\end{array}$ & $\begin{array}{c}\text { Total } \\
\text { Interfacial } \\
\text { area }\left(\mathrm{m}^{2}\right)\end{array}$ & $\begin{array}{l}\text { Number of } \\
\text { NPs per } \\
\text { droplet area }\end{array}$ & $\begin{array}{l}\text { Fraction } \\
\text { covered }\end{array}$ & $\begin{array}{l}\text { PIONP } \\
\text { efficiency }\end{array}$ \\
\hline 5.09 & 25.1 & $8.65 \times 10^{-4}$ & 2206 & 23.4 & 0.253 & 3.00 & 17.0 & 71.1 & $6.66 \times 10^{14}$ & 0.329 & 3.04 \\
\hline
\end{tabular}


Extended Data Table 3| Quantification of PIONP surface coverage on the whole interface of macroemulsion droplets including submicron droplets, small droplets and large droplets

\begin{tabular}{cccccccccc}
\hline $\begin{array}{c}\text { Concentration } \\
\text { (PIONPs wt } \% \text { in }\end{array}$ & $\begin{array}{c}\text { PIONP } \\
\text { size } \\
\text { aqueous phase })\end{array}$ & $\begin{array}{c}\text { PIONP mass } \\
(\mathrm{nm})\end{array}$ & $\begin{array}{c}\text { PIONP } \\
\text { covered } \\
\text { area }\left(\mathrm{m}^{2)}\right.\end{array}$ & $\begin{array}{c}\text { Oil droplet } \\
\text { type }\end{array}$ & $\begin{array}{c}\text { Sauter droplet } \\
\text { size }(\mu \mathrm{m})\end{array}$ & $\begin{array}{c}\text { Oil } \\
(\mathrm{mL})\end{array}$ & $\begin{array}{c}\text { Total } \\
\text { Interfacial } \\
\text { area }\left(\mathrm{m}^{2}\right)\end{array}$ & $\begin{array}{c}\text { Fraction } \\
\text { covered }\end{array}$ & $\begin{array}{c}\text { PIONP } \\
\text { efficiency }\end{array}$ \\
\hline 0.020 & 25.1 & $1.00 \times 10^{-6}$ & $2.71 \times 10^{-2}$ & whole & 21.1 & 5.00 & 1.43 & 0.019 \\
0.040 & 25.1 & $2.00 \times 10^{-6}$ & $5.42 \times 10^{-2}$ & whole & 11.7 & 5.01 & 2.56 & 0.021 & 47.3 \\
0.060 & 25.1 & $3.00 \times 10^{-6}$ & $8.13 \times 10^{-2}$ & whole & 8.40 & 5.01 & 3.58 & 0.023 & 44.0 \\
0.100 & 25.1 & $5.00 \times 10^{-6}$ & $1.35 \times 10^{-1}$ & whole & 6.82 & 5.02 & 4.42 & 0.031 & 32.6 \\
0.150 & 25.1 & $7.50 \times 10^{-6}$ & $2.03 \times 10^{-1}$ & whole & 6.00 & 5.03 & 5.02 & 0.040 & 24.7 \\
\hline
\end{tabular}


Extended Data Table 4| Quantification of submicron droplet surface coverage on small droplets, large droplets and the whole interface of macroemulsion

\begin{tabular}{|c|c|c|c|c|c|c|c|c|c|c|}
\hline $\begin{array}{c}\text { PIONPs } \\
(w t \%)\end{array}$ & $\begin{array}{l}\text { Submicron } \\
\text { droplet size } \\
\quad(\mu \mathrm{m})\end{array}$ & $\begin{array}{c}\text { Submicron } \\
\text { droplet } \\
\text { number }\end{array}$ & $\begin{array}{c}\text { Submicron droplet } \\
\text { interfacial area } \\
\left(\mathrm{m}^{2}\right)\end{array}$ & $\begin{array}{c}\text { Total } \\
\text { covered } \\
\text { area }\left(\mathrm{m}^{2}\right)\end{array}$ & $\begin{array}{c}\text { Droplet } \\
\text { type }\end{array}$ & $\begin{array}{c}\text { Sauter } \\
\text { droplet } \\
\text { size }(\mu \mathrm{m})\end{array}$ & $\begin{array}{c}\text { Oil } \\
(\mathrm{mL})\end{array}$ & $\begin{array}{c}\text { Total } \\
\text { interfacial } \\
\text { area }\left(\mathrm{m}^{2}\right)\end{array}$ & $\begin{array}{l}\text { Fraction } \\
\text { covered }\end{array}$ & $\begin{array}{l}\text { Submicron } \\
\text { droplet } \\
\text { efficiency }\end{array}$ \\
\hline \multirow{4}{*}{0.020} & \multirow{3}{*}{0.253} & \multirow{3}{*}{$4.07 \times 10^{11}$} & \multirow{3}{*}{0.082} & \multirow{3}{*}{$2.05 \times 10^{-2}$} & small & 1.33 & 0.136 & 0.613 & 0.033 & 7.50 \\
\hline & & & & & large & 40.0 & 4.86 & 0.730 & 0.028 & 35.7 \\
\hline & & & & & whole & 22.3 & 5.00 & 1.34 & 0.015 & 65.7 \\
\hline & \multirow{3}{*}{0.253} & \multirow{3}{*}{$8.14 \times 10^{11}$} & \multirow{3}{*}{0.164} & \multirow{3}{*}{$4.09 \times 10^{-2}$} & small & 1.33 & 0.243 & 1.09 & 0.076 & 7.69 \\
\hline \multirow[t]{2}{*}{0.040} & & & & & large & 21.9 & 4.76 & 1.30 & 0.031 & 31.9 \\
\hline & & & & & whole & 12.5 & 5.00 & 2.40 & 0.017 & 58.6 \\
\hline \multirow{3}{*}{0.060} & \multirow{3}{*}{0.253} & \multirow{3}{*}{$1.22 \times 10^{12}$} & \multirow{3}{*}{0.245} & \multirow{3}{*}{$6.13 \times 10^{-2}$} & small & 1.33 & 0.337 & 1.52 & 0.081 & 7.20 \\
\hline & & & & & large & 15.4 & 4.66 & 1.81 & 0.034 & 29.5 \\
\hline & & & & & whole & 9.00 & 5.00 & 3.33 & 0.018 & 54.3 \\
\hline \multirow{3}{*}{0.100} & \multirow{3}{*}{0.253} & \multirow{3}{*}{$2.03 \times 10^{12}$} & \multirow{3}{*}{0.409} & \multirow{3}{*}{$1.02 \times 10^{-1}$} & small & 1.33 & 0.405 & 1.83 & 0.056 & 5.47 \\
\hline & & & & & large & 12.7 & 4.59 & 2.18 & 0.047 & 21.3 \\
\hline & & & & & whole & 7.50 & 5.00 & 4.01 & 0.026 & 39.2 \\
\hline \multirow{3}{*}{0.150} & \multirow{3}{*}{0.253} & \multirow{3}{*}{$3.04 \times 10^{12}$} & \multirow{3}{*}{0.612} & \multirow{3}{*}{$1.53 \times 10^{-1}$} & small & 1.33 & 0.446 & 2.01 & 0.076 & 4.29 \\
\hline & & & & & large & 11.4 & 4.55 & 2.40 & 0.064 & 15.7 \\
\hline & & & & & whole & 6.80 & 5.00 & 4.41 & 0.035 & 28.8 \\
\hline
\end{tabular}


Extended Data Table 5| Comparison of different particles (PIONPs and reporting silica NPs) needed for stabilizing macroemulsion droplets

\begin{tabular}{|c|c|c|c|c|c|c|c|c|c|c|}
\hline $\begin{array}{l}\text { Stabilization } \\
\text { mode }\end{array}$ & $\begin{array}{l}\text { Particle } \\
\text { type }\end{array}$ & $\begin{array}{l}\text { Particle } \\
\text { size } \\
\text { (nm) }\end{array}$ & $\begin{array}{c}\text { Initial particle } \\
\text { concentration in } \\
\text { aqueous phase }\end{array}$ & $\begin{array}{c}\text { Particle } \\
\text { covered } \\
\text { area }\left(\mathrm{m}^{2}\right)\end{array}$ & $\begin{array}{c}\text { Sauter } \\
\text { droplet } \\
\text { size }(\mu \mathrm{m})\end{array}$ & $\begin{array}{l}\text { Total } \\
\text { interfacial } \\
\text { area }\left(\mathrm{m}^{2}\right)\end{array}$ & $\begin{array}{l}\text { Number/ } \\
\text { droplet } \\
\text { area }\end{array}$ & $\begin{array}{l}\text { Fraction } \\
\text { covered }\end{array}$ & $\begin{array}{l}\text { Particle } \\
\text { efficiency }\end{array}$ & Ref. \\
\hline \multirow{5}{*}{ Hierarchy } & \multirow{5}{*}{$\begin{array}{l}\text { Polymer- } \\
\text { coated IO } \\
\text { (PIONPs) }\end{array}$} & \multirow{5}{*}{25.1} & $0.020 \mathrm{wt}^{0} \%$ & $2.71 \times 10^{-2}$ & 21.1 & 1.43 & $3.84 \times 10^{13}$ & 0.019 & 52.6 & \\
\hline & & & $0.040 \mathrm{wt} \%$ & $5.42 \times 10^{-2}$ & 11.7 & 2.56 & $4.27 \times 10^{13}$ & 0.021 & 47.3 & \\
\hline & & & $0.060 \mathrm{wt} \%$ & $8.13 \times 10^{-2}$ & 8.40 & 3.58 & $4.59 \times 10^{13}$ & 0.023 & 44.0 & \\
\hline & & & $0.100 \mathrm{wt} \%$ & $1.35 \times 10^{-1}$ & 6.82 & 4.42 & $6.20 \times 10^{13}$ & 0.031 & 32.6 & \\
\hline & & & $0.150 \mathrm{wt} \%$ & $2.03 \times 10^{-1}$ & 6.00 & 5.02 & $8.18 \times 10^{13}$ & 0.040 & 24.7 & \\
\hline \multirow{5}{*}{$\begin{array}{c}\text { Steric } \\
\text { hindrance }\end{array}$} & Hexamethyld & \multirow{5}{*}{75.0} & $0.330 \mathrm{w} / \mathrm{v} \%$ & 0.499 & 121.3 & 0.989 & $1.14 \times 10^{14}$ & 0.505 & 1.98 & \multirow{5}{*}{23} \\
\hline & isilazane & & $1.00 \mathrm{w} / \mathrm{v} \%$ & 1.51 & 41.5 & 2.89 & $1.18 \times 10^{14}$ & 0.523 & 1.91 & \\
\hline & (HDMS) & & $2.00 \mathrm{w} / \mathrm{v} \%$ & 3.03 & 23.7 & 5.06 & $1.35 \times 10^{14}$ & 0.598 & 1.67 & \\
\hline & modified & & $3.00 \mathrm{w} / \mathrm{v} \%$ & 4.54 & 14.4 & 8.33 & $1.23 \times 10^{14}$ & 0.545 & 1.84 & \\
\hline & Silica & & $3.70 \mathrm{w} / \mathrm{v} \%$ & 5.60 & 8.6 & 14.0 & $9.08 \times 10^{13}$ & 0.505 & 2.49 & \\
\hline Steric & Polymer- & & $0.500 \mathrm{wt} \%$ & 0.256 & 13.5 & 0.360 & $9.05 \times 10^{15}$ & 0.711 & 1.41 & \multirow{3}{*}{24} \\
\hline \multirow[t]{2}{*}{ hindrance } & coated silica & 10.0 & $1.00 \mathrm{wt} \%$ & 0.649 & 5.74 & 0.870 & $9.50 \times 10^{15}$ & 0.746 & 1.34 & \\
\hline & & & $5.00 \mathrm{wt} \%$ & 1.66 & 2.58 & 2.16 & $9.76 \times 10^{15}$ & 0.766 & 1.30 & \\
\hline Bridge & $\begin{array}{c}\text { Fluorescent } \\
\text { silica }\end{array}$ & 510 & $0.500 \mathrm{wt} \%$ & 0.163 & 30 & 3.00 & $2.67 \times 10^{11}$ & 0.055 & 18.4 & 19 \\
\hline
\end{tabular}

